\title{
Plasmid-Encoded Iron Uptake Systems
}

MANUELA DI LORENZO${ }^{1}$ and MICHIEL STORK ${ }^{2}$

${ }^{1}$ Netherlands Institute of Ecology (NIOO-KNAW), Department of Microbial Ecology, 6708 PB Wageningen, The Netherlands; 'Institute for Translational Vaccinology, Process Development, 3720 AL Bilthoven, The Netherlands

\begin{abstract}
Plasmids confer genetic information that benefits the bacterial cells containing them. In pathogenic bacteria, plasmids often harbor virulence determinants that enhance the pathogenicity of the bacterium. The ability to acquire iron in environments where it is limited, for instance the eukaryotic host, is a critical factor for bacterial growth. To acquire iron, bacteria have evolved specific iron uptake mechanisms. These systems are often chromosomally encoded, while those that are plasmid-encoded are rare. Two main plasmid types, ColV and PJM1, have been shown to harbor determinants that increase virulence by providing the cell with essential iron for growth. It is clear that these two plasmid groups evolved independently from each other since they do not share similarities either in the plasmid backbones or in the iron uptake systems they harbor. The siderophores aerobactin and salmochelin that are found on ColV plasmids fall in the hydroxamate and catechol group, respectively, whereas both functional groups are present in the anguibactin siderophore, the only iron uptake system found on pJM1-type plasmids. Besides siderophore-mediated iron uptake, ColV plasmids carry additional genes involved in iron metabolism. These systems include $A B C$ transporters, hemolysins, and a hemoglobin protease. ColV- and pJM1-like plasmids have been shown to confer virulence to their bacterial host, and this trait can be completely ascribed to their encoded iron uptake systems.
\end{abstract}

\section{INTRODUCTION}

Iron is one of the most important metals for life, as it is necessary for the proper functioning of proteins that mediate essential cellular processes such as DNA precursor synthesis, respiration, photosynthesis, and nitrogen fixation. Iron is one of the most abundant elements on earth; however, its bioavailability is very low. In the presence of oxygen, ferrous iron oxidizes to ferric iron that is poorly soluble at neutral $\mathrm{pH}$. Additionally, free iron is toxic due to the formation of free oxygen radicals that can cause cell damage (1). Therefore, in biological systems the iron is complexed to keep it soluble and to reduce the toxicity of free iron.

To overcome the low availability of iron in their environment, bacteria have evolved specialized mechanisms to take up either the scarce soluble ions or to compete with iron-chelating complexes (2). In particular, pathogenic bacteria face extremely low iron concentrations due to the presence of high-affinity iron-binding proteins in the host that perform a dual function: they protect cells from the toxic effect of free iron while inhibiting bacterial growth (ㄱ) $)$. Competition for iron within the host is thus a critical factor in host-pathogen interaction (4).

Mechanisms for iron uptake range from direct binding of transferrin, lactoferrin, and heme by outer membrane receptors, to compounds with a high affinity for iron that strip the metal ions chelated to protein and complexes ( $\underline{5})$. To take up iron from the host ironbinding proteins transferrin and lactoferrin, bacteria express specific outer membrane receptors. Upon binding to the receptor, iron is released and transported through the receptor to the periplasmic space and subsequently

Received: 30 September 2014, Accepted: 1 October 2014

Published: 5 December 2014

Editors: Marcelo Tolmasky, California State University, Fullerton, CA, and Juan Carlos Alonso, Centro Nacional de Biotecnología, Cantoblanco, Madrid, Spain

Citation: Di Lorenzo M, Stork M. 2014. Plasmid-encoded iron uptake systems. Microbiol Spectrum 2(6):PLAS-0030-2014. doi:10.1128/ microbiolspec.PLAS-0030-2014.

Correspondence: Manuela Di Lorenzo, m.dilorenzo@nioo.knaw.nl (c) 2014 American Society for Microbiology. All rights reserved. 
to the cytoplasm $(\underline{6}, \underline{7})$. Bacteria can also obtain iron from red blood cells via similar though more complex mechanisms. Hemoglobin and heme are released from hematocytes by the action of cytolysins and hemolysins. Receptors at the bacterial surface recognize the free heme or hemoproteins and transport heme to the periplasm. Once inside the cell, iron is released from heme (). . More elaborate heme acquisition systems secrete heme-scavenging molecules, the hemophores, which extract heme from host hemoproteins and deliver it to an outer membrane receptor for internalization ( $\underline{8})$.

Siderophore-mediated systems are the most studied iron uptake mechanism of bacteria. Siderophores are low-molecular-weight compounds that have a very high association constant for iron, up to $10^{50}$ (9). Most of these secondary metabolites are synthesized via a nonribosomal peptide synthetase mechanism (10). Siderophores are produced in the cytoplasm and then secreted to the extracellular space. Outside the cell, the siderophore competes for iron with iron complexes, such as the iron-binding proteins lactoferrin and transferrin in the host $(11,12)$. Iron-loaded siderophores are bound by cognate receptors, and iron is internalized via a specific uptake system in the membrane of the bacterium (13). The uptake of ferric-siderophores by the bacterium is initiated by a chance encounter of the bacterial outer membrane receptor with the iron-loaded siderophore.

In all cases, transport of iron across the membranes needs energy. In Gram-negative bacteria there is no energy generation in the outer membrane, so the energy required to cross it is provided by the inner membrane. The proton motive force of the inner membrane is transduced to the outer membrane receptors by the TonB complex. This complex consists of several proteins (TonB, ExbB, ExbD, and in some cases TtpC) that are always chromosomally encoded (14-17). Once the iron or iron complex is in the periplasm, periplasmic binding proteins, either soluble or membrane-bound through a lipid anchor, mediate delivery to a complex in the inner membrane that usually belongs to the ATP-binding cassette $(\mathrm{ABC})$ transporter family. The $\mathrm{ABC}$ transporters consist of two inner membrane permeases and an ATPase that hydrolyzes ATP to energize transport of the ligand across the cytoplasmic membrane (18).

While outer membrane receptors are highly specific for the system they belong to, the rest of the proteins involved in transport into the cytosol are often interchangeable between different iron uptake systems (18). Once it is in the cytoplasm, iron can be used for immediate cellular needs or stored in bacterioferritins (19).
The gene products involved in iron uptake are tightly regulated by iron availability. In iron-replete environments the genes are repressed by the ferric uptake regulator (Fur) (20-22). Fur in complex with iron binds to specific DNA sequences at the promoter regions of iron-regulated genes and blocks transcription. When iron is limiting, Fur no longer contains iron and therefore cannot bind the DNA. As a consequence, Fur repression is released and transcription proceeds (22). In addition to Fur, expression of iron uptake genes is also controlled by numerous small RNAs as well as regulatory proteins and two component systems $(\underline{23}, 24)$.

Most bacteria have at least one iron uptake mechanism, although the presence of multiple systems is quite common. Although the majority of these systems are chromosomally encoded, some of them are plasmidmediated (25). The most studied plasmids harboring iron uptake systems are the ColV plasmids, found mainly in Enterobacteriaceae, and the pJM1-type plasmids, found in Vibrio anguillarum strains. Interestingly, there is no homology between these two plasmids and the systems they carry (26). In this article, we describe these two plasmid types and their iron uptake systems.

\section{CoIV PLASMIDS}

ColV plasmids are large and belong to the IncFI incompatibility group. Plasmids in this group are heterogeneous in size (typically from 80 to $180 \mathrm{~kb}$ ), genetic composition, ability to conjugate, and virulence properties (27).

These plasmids often possess more than one IncF replicon, but the replicons and their genetic organization are not always conserved across the different plasmids. The repFIB replicon is the most widespread among ColV plasmids, and it is located between the sit $A B C D$ and the ets $A B C$ regions (27-31). The repFIB replicon of pColV-K30 encodes two essential factors for replication: an initiator protein, RepI, and five 18-bp direct repeats (32-34). It has been proposed that upon binding to the direct repeats at the origin of replication, RepI facilitates the opening of the DNA helix, initiating replication. Furthermore, when bound to the origin, RepI also represses its own expression $(35,36)$. Another replicon is commonly found in proximity to the transfer region; while in most cases this is a repFIIA replicon, in plasmids pAPEC-1 and pAPEC-O1-ColBM a composite repFIIArepFIC origin is present $(28, \underline{31})$. Some ColV plasmids also carry a replicon homologous to repFIA of plasmid $\mathrm{F}$ (37). In these instances, a genetic organization with the two replicons repFIA and repFIB flanking the aerobactin 
system seems to be conserved even in non-ColV plasmids, such as Escherichia coli R plasmids (ㅎ8).

ColV plasmids have long been associated with the virulence of extraintestinal pathogenic E. coli, ExPEC $(29,39)$. This group of pathogenic E. coli has acquired numerous virulence traits, which confer the ability to cause an infection outside the host intestinal tract. The ExPEC group includes human and animal pathogens that cause urinary tract infections, neonatal meningitis, and septicemia. Avian pathogenic E. coli (APEC) strains are also ExPEC, and ColV plasmids are a defining feature of the APEC pathotype (40). ColV plasmids have also been identified at high frequencies in strains of Salmonella enterica serovar Kentucky isolated from chickens $(\underline{41}, \underline{42})$.

ColV plasmids owe their name to colicin V, a toxin that is active against E. coli, Shigella, and Salmonella strains. It was first described by Andre Gratia in 1925 (43) and later shown to be transferable and linked to F-type plasmids $(44, \underline{45})$. Colicin V, the first identified colicin, is a microcin, a low-molecular-weight peptide antibiotic secreted through a dedicated $\mathrm{ABC}$ transporter $(46,47)$. Colicin V exerts bactericidal activity only at the periplasmic face of the inner membrane, where it interferes with energy production by disrupting the membrane potential (뇨). Four plasmid-encoded genes (cvaA, $c v a B, c v a C$, and $c v i)$ are involved in colicin synthesis, export, and immunity (Fig. 1). In addition, two chromosome-encoded genes ( $c \nu p A$ and tolC) are required for production and secretion $(\underline{46}, 49)$. Colicin $\mathrm{V}$ is often found in association with colicin Ia (50). Plasmid pS88 is an example of a plasmid harboring colicin $\mathrm{V}$ and colicin Ia operons (51). Colicin Ia has the same mode of action as colicin $\mathrm{V}$, but while the production of colicin Ia is induced under stress conditions, the expression of colicin $\mathrm{V}$ is regulated by iron $(\underline{49}, \underline{52})$.

Other colicin-encoding plasmids have been identified among ExPEC and APEC, the ColBM plasmids. These plasmids have received less attention than the more widespread ColV plasmids, but recent studies have shown that the ColBM plasmids harbor virulence clusters similar to those present on ColV plasmids. Analyses of the available sequences of ColBM plasmids suggest that they have evolved from an ancestral ColV plasmid by insertion of the ColBM region within the ColV operon. In fact, high DNA homology between the plasmids pAPEC-O2-ColV and pAPEC-O1-ColBM is observed in the virulence clusters, and $67 \%$ of the predicted proteins of pAPEC-O1-ColBM are also found on pAPEC-O2ColV (28). These two plasmids also have nearly identical transfer regions and possess repFIB and repFIIA replicons
(28). Alternatively, transfer of the colicin $\mathrm{V}$ genes and associated virulence factors onto ColBM plasmids could have occurred (53).

The ColBM region harbors the ColB and ColM operons. These two operons encode colicin B and colicin $\mathrm{M}$, respectively. Each operon consists of a structural gene for the colicin ( $c b a$ in ColB and $c m a$ in ColM) and an immunity gene ( $c b i$ in ColB and $c m i$ in ColM) encoding a protein that binds and inactivates the colicin. Colicin B is a pore-forming colicin and has a mode of action similar to colicin V (49), while colicin M, the smallest known colicin, inhibits peptidoglycan biosynthesis (54). Interestingly, both colicins, as well as colicin V and Ia, gain access to sensitive cells via TonB-dependent receptors: the enterobactin receptor FepA for colicin B, the ferrichrome receptor FhuA for colicin $\mathrm{M}$, and the catechol receptor Cir for colicin V and colicin Ia $(\underline{47}, 55)$. The use of iron-regulated receptors for internalization and their iron-regulated expression show the intimate link between colicins and iron. Colicin-producing cells might have an advantage in iron-limited environments, since development of resistance in sensitive cells might occur at the cost of iron uptake efficiencies since it could mean the loss of TonB-dependent receptors (47).

Despite their name, it was shown early on that the virulence phenotype conferred by the ColV and ColBM plasmids is not colicin-mediated $(56,57)$. Several other determinants that are present in different combinations in the various plasmids of the ColV group have been shown to contribute to virulence. ColV plasmids harbor genes that encode serum resistance, adherence, resistance to chlorine and disinfectants, bacteriophage resistance, hemagglutination properties, and several iron acquisition systems (29). The presence of several clusters involved in iron metabolism is not surprising when considering the extraintestinal lifestyle of ExPEC strains, where iron is one of the main limiting factors for colonizing bacteria.

\section{Aerobactin Iron Uptake System}

The first ColV iron uptake system identified was the one that codes for the hydroxamate siderophore aerobactin and its outer membrane receptor (58). The aerobactin system is, together with colicin V, the hallmark of ColV plasmids. Aerobactin was first discovered in the supernatant of Aerobacter aerogenes 62-I and was later shown to be encoded by plasmid pSMN1 $(\underline{59}, 60)$. Even though they are both plasmid-encoded, the aerobactin cluster of pSMN1 shares only a weak homology with the genes encoding the aerobactin system found on the ColV plasmids (61). These two genetically distinct systems 


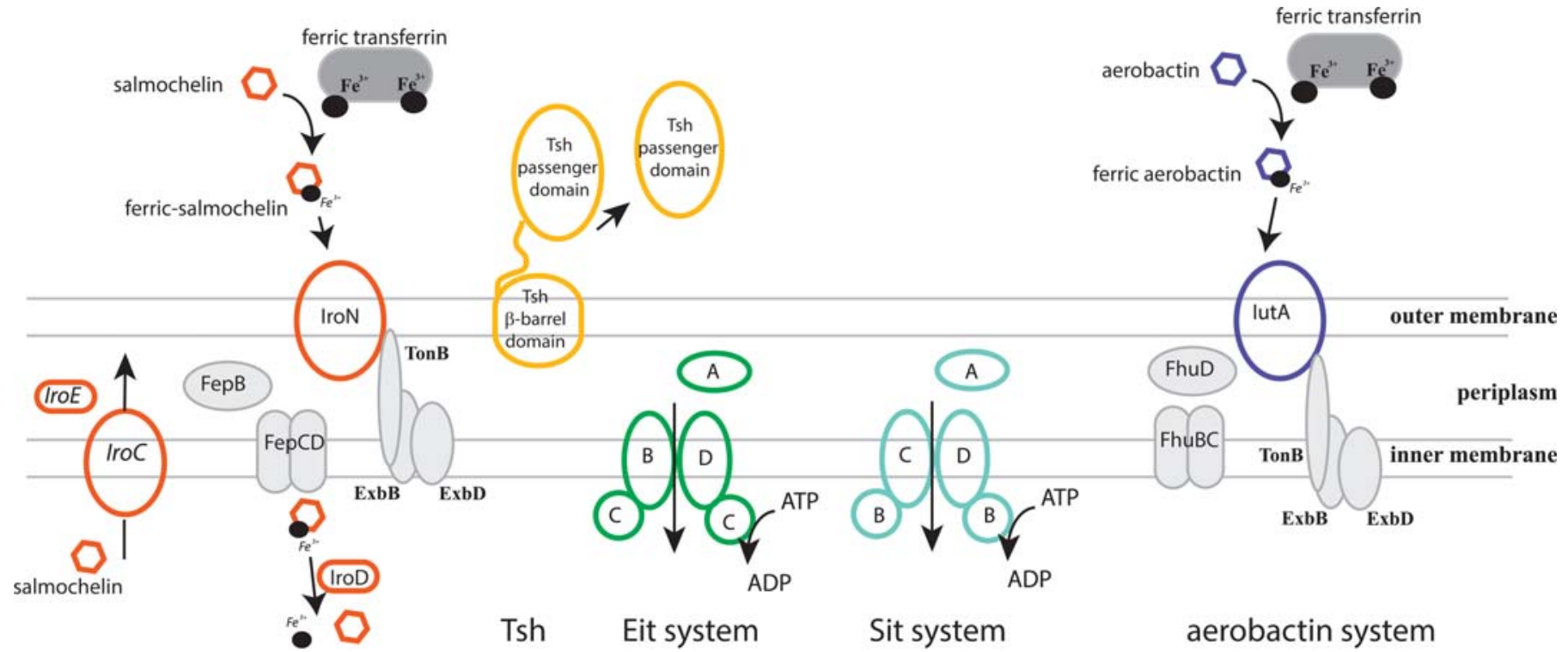

salmochelin system

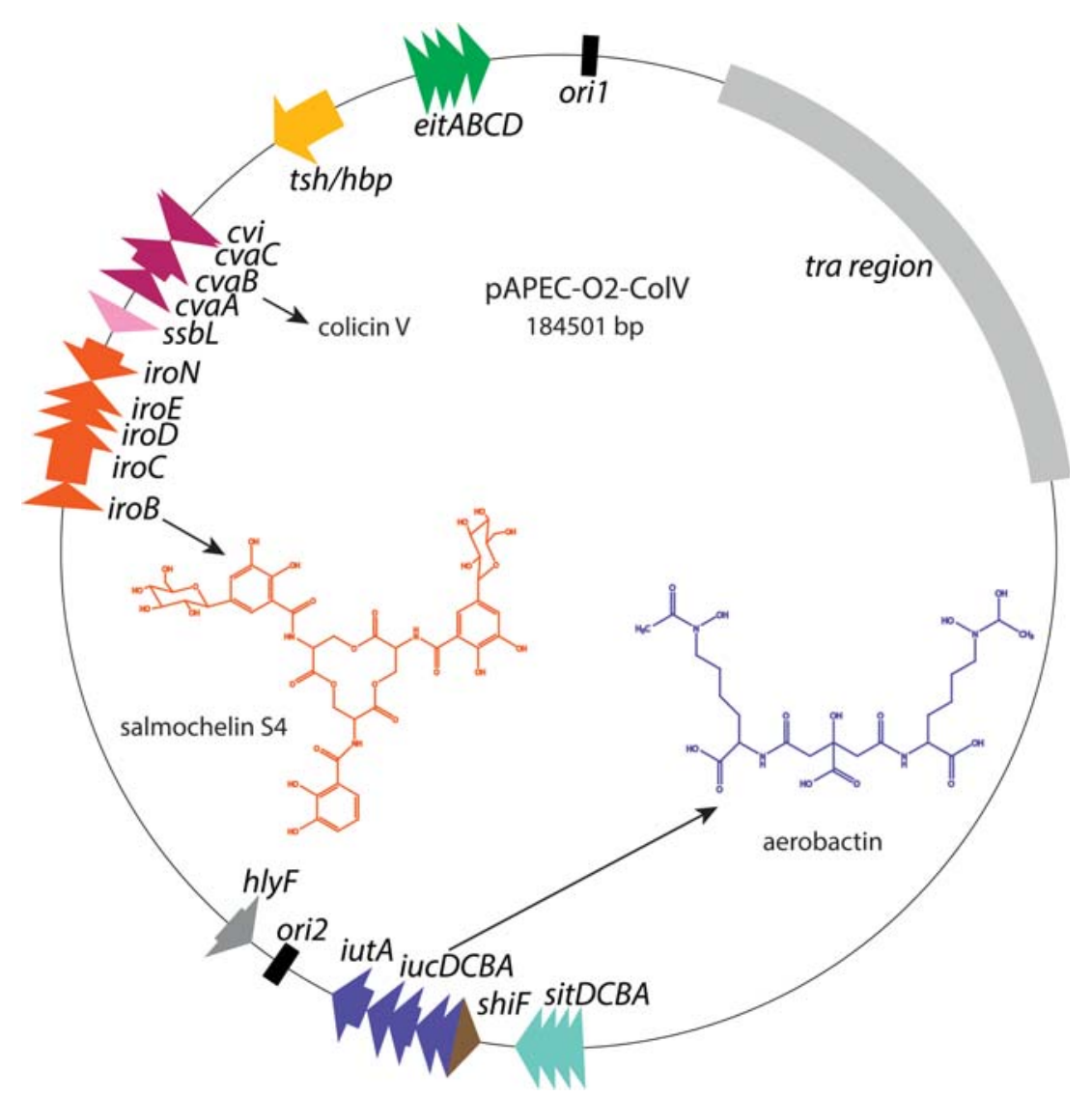

FIGURE 1 Schematic representation of a ColV plasmid (30) showing all open reading frames related to iron uptake, their function, and their membrane localization when relevant. Each system is color-coded. The tra region is shown as a gray box, and the origins of replication are shown as black boxes. Structures of the two siderophores aerobactin and salmochelin S4 are shown within the plasmid. doi:10.1128/microbiolspec.PLAS-0030-2014.f1 
nonetheless produce siderophores with identical structures. Interestingly, the aerobactin cluster is also found on non-ColV R plasmids of Salmonella and E. coli (38, $60,62,63)$. In contrast to the case of pSMN1, the aerobactin sequences found on ColV and E. coli and Salmonella $\mathrm{R}$ plasmids are conserved and linked to the repFIB replication region $(37,62)$. It is worth noting that the origin of replication of plasmid pSMN1 is not of the IncFI incompatibility group (61), which suggests a linkage between the repFIB origin of replication and the aerobactin cluster found on ColV and R plasmids. They could constitute a virulence factor-replication unit that ensures perpetuation of the aerobactin genes even in the event of a deletion (37). The aerobactin system was also found in close proximity to the repFIB replicon in Chronobacter virulence plasmid and in a plasmid isolated from a sewage treatment plant (64-66).

The aerobactin genes in ColV and Salmonella R plasmids are flanked by the inverted IS1 sequences that could contribute to the spread of this system either by homologous recombination with other IS1 sequences or by transposition $(37,67,68)$. The increased mobility conferred by the flanking IS1 sequences could explain the occurrence of the aerobactin system also on chromosomes of E. coli, Salmonella, and Shigella strains (60, 69-73). The presence of a colicin system within the pathogenicity island (PAI) of Shigella flexneri upstream of the aerobactin genes further supports the hypothesis of a ColV origin for the chromosomal systems (73). On the other hand, the absence of flanking IS1 sequences both on plasmid- and chromosome-encoded aerobactin systems as well as some sequence divergence, might argue against an IS1-mediated mechanism of dissemination and a ColV origin $(\underline{74}, \underline{75})$.

The gene cluster of the aerobactin system consists of five open reading frames, iucABCDiutA (Fig. 1) (6). The products of the iuc genes are involved in the biosynthesis of aerobactin from lysine and citrate. The citrate molecule serves as a central linker for two molecules of $N^{6}$-acetyl- $N^{6}$-hydroxy lysine. These molecules are produced from lysine in two steps. In the first step, the IucD monooxygenase utilizes molecular oxygen to generate $N^{6}$-hydroxy lysine. In the subsequent step, the acetylase IucB $\mathrm{N}$-acetylates the hydroxy lysine using acetyl-CoA (77). The final coupling of two molecules of $N^{6}$-acetyl- $N^{6}$-hydroxy lysine to citrate is catalyzed by the two synthetases IucA and IucC. Each synthetase assembles one modified lysine molecule onto the citrate, forming an amide bond between the $\alpha$-amino group of lysine and the carbon of one of the carboxyl groups of citrate (78). The last gene of the cluster, iutA, encodes the outer membrane receptor for ferric aerobactin that functions in a TonB-dependent manner (79). Once in the periplasm, aerobactin is bound and transported across the inner membrane by the generic chromosomally encoded hydroxamate transport system, which consists of a periplasmic binding protein, $\mathrm{FhuD}$, and inner membrane permeases, FhuBC (0ㅛㄹㅡ). The clusters coding for the TonB complex and the hydroxamate transport system are both located on the chromosome (ㅈ3).

Like other iron uptake systems, expression of the aerobactin cluster is negatively regulated by Fur and the iron state of the cell (84). Fur binds in an iron-dependent manner to multiple sites within a large region of the aerobactin operon promoter ( $\underline{85})$.

Several pieces of evidence point to aerobactin as a virulence factor. A large percentage of E. coli strains isolated from human extraintestinal infections tested positive for aerobactin, while only one-third of normal fecal isolates carried genes of the aerobactin system $(\underline{86}$, 87). Among avian E. coli isolates, only the most virulent harbor the aerobactin genes, while these same genes are absent from nonvirulent and nonlethal isolates $(\underline{88}, \underline{89})$. Furthermore, aerobactin genes were expressed during infection, and defined deletion mutants in biosynthetic and transport genes resulted in decreased virulence in a chicken infection model (90-92). In whole-plasmid transcriptional studies, an additional gene, shiF, was upregulated during growth in human serum and urine and in a neonatal rat sepsis model $(93,94)$. The shiF gene has been found to be conserved upstream of the aerobactin cluster, in some cases in association with another gene, viuB $(51,64-66)$. Based on their homology, the products of these two genes have been proposed to be part of the aerobactin iron uptake system $(\underline{64}-66,93)$.

\section{Salmochelin Iron Uptake System}

The salmochelin iron uptake system, encoded on the chromosome of Salmonella species and of several uropathogenic E. coli (UPEC) (95-98), has been recently associated with the ColV plasmids of APEC strains (90, 92, 99, 100) as well as with non-ColV transmissible plasmids of UPEC and Klebsiella strains $(101,102)$.

Salmochelins are catechol siderophores that consist of enterobactin glucosylated at one or two of the 2,3dihydroxybenzoyl (DHB) rings (103). Salmochelin S4 (Fig. 1), the most common form, has the macrolactone of enterobactin intact, while this is hydrolyzed in salmochelin S2, where the unglycosylated DHB-serine moiety is located at the C-terminal end. Salmochelins S1 and $\mathrm{SX}$ are, respectively, the dimer $\mathrm{DHB}$ (gucosyl)-seryl$\mathrm{DHB}$-serine and the monomeric $\mathrm{DHB}$ (glucosyl)-serine 
molecule. All these salmochelin forms have been isolated from $S$. enterica growth medium, but as in the case of enterobactin, these linear forms are probably the degradation products of salmochelin S4, the key metabolite (103). Since the substrate for salmochelin S4 synthesis is enterobactin itself, genes of the enterobactin cluster are also essential for salmochelin biosynthesis $(103,104)$. Glycosylation of enterobactin results in a siderophore with reduced hydrophobicity that is no longer recognized and bound by the host protein siderocalin and serum albumin $(103,105,106)$. Perhaps immunologic pressure in serum resulted in a selective advantage for strains harboring salmochelin over those producing enterobactin.

Genes coding for salmochelins and the outer membrane receptor were first identified in the chromosome of Salmonella serovar Typhimurium in the Fur-regulated locus, iroA (96). The iroA locus consists of two divergently transcribed sets of genes, iroBCDE and iroN (95).

IroN is an outer-membrane protein with homology to TonB-dependent receptors. IroN is the receptor for salmochelins, as shown by uptake experiments with radiolabeled ${ }^{55} \mathrm{~F}$-salmochelin and growth promotion assays (107). Salmochelin uptake can also be facilitated by the enterobactin receptor FepA and the Cir receptor in Salmonella (107). On the other hand, IroN can transport, besides salmochelins, other catechol siderophores, such as enterobactin and corynebactin $(102,108)$. An additional role as an internalization factor has been proposed for IroN during invasion of urothelial cells by ExPEC strains (109).

The iro $B$ gene is the only one in the iro $A$ cluster involved in salmochelin biosynthesis (Fig. 1). IroB encodes a glucosyltransferase that glucosylates the $\mathrm{DHB}$ rings of enterobactin using UDP-Glc as the glycosyl donor. A remarkable characteristic of IroB is the ability to catalyze formation of a C-C bond during enterobactin glucosylation. In this regard, IroB differs from other glycosyltransferases, such as those identified in the antibiotics vancomycin and ramoplanin, which glycosylate oxygen atoms (104).

The iro $C$ gene encodes a four-domain $\mathrm{ABC}$ exporter similar to eukaryotic multidrug resistance transporters (Fig. 1). IroC is involved in salmochelin S4 secretion rather than in the uptake of ferric-salmochelin, as shown by deletion of the iroC gene $(\underline{110}, 111)$.

The last two genes in the iroBCDE operon encode two proteins, IroD and IroE, which are predicted to have hydrolytic activity. IroD is a cytoplasmic protein similar to Fes, the esterase of the enterobactin system. IroE is instead predicted to be a periplasmic esterase. The function of these two esterases in the salmochelin system is still not well established as well as their substrate specificity. Most likely, IroD is the esterase responsible for release of iron from ferric-salmochelin into the cytoplasm. IroE acts in the periplasm and might be more important for export or processing of cyclic salmochelins prior to release $(99,110$, 112).

Besides the iroBCDE and iroN plasmid-encoded genes, the entire chromosomally encoded enterobactin cluster is required for salmochelin biosynthesis and transport (113). In addition, the chromosomally encoded TonB complex is needed to transport salmochelin across the outer membrane.

It has been shown that salmochelin is required for full virulence in a chicken infection model (90). Mutations in the salmochelin system slightly affect virulence, while mutations in multiple iron uptake systems result in a dramatic decrease of chicken tissue colonization (91, 114). This is probably due to the high redundancy of iron uptake systems in pathogenic strains. Levels of salmochelin produced during infection of host tissues are similar to those produced in iron-poor culture medium (110). Although salmochelin levels are lower than the aerobactin levels, both in vitro and in vivo, production of salmochelin in vivo further supports a role in virulence for this siderophore. Transcriptional studies in human serum and urine point to a similar role of the salmochelin system found on plasmid pS88 of an E. coli strain that causes neonatal meningitis (93). Interestingly, in the same study a gene, $s s b L$, was identified that displayed the highest upregulation in vivo. The ssbL gene shows a strong association with the iro cluster (115). The $s s b L$ gene is involved in the shikimate pathway, and its product has been proposed to enhance production of salmochelin by boosting the catechol metabolic pathway (115).

\section{SitABCD Iron Transport System}

Operons encoding the SitABCD system have been found on the reference colicin $\mathrm{V}$ plasmid pColV-K30 and on ColV-like plasmids of APEC strains (28, 30, 31, 116, 117).

The SitABCD system is an ATP-binding cassette $(\mathrm{ABC})$ transporter of divalent metal cations, originally identified on the chromosome of serovar Typhimurium in Salmonella PAI1, SPI1 (118). As in typical ABC transport systems, the sit genes encode a periplasmic protein, SitA, that binds the ligand and transfers it to the inner membrane permeases, SitC and SitD (Fig. 1). SitB, the ATPase of the system, catalyzes hydrolysis of ATP to energize transport across the cytoplasmic membrane of the ligand (119). 
The sit $A B C D$ operon is expressed in vivo during the systemic stages of Salmonella serovar Typhimurium infection in mice. A mutation in the sit locus resulted in a defect in virulence of the mutant strain, although it was subtle, probably due to the presence of redundant systems for iron and manganese uptake (120). After its initial identification as a siderophore-independent iron $\mathrm{ABC}$ transporter, the Sit system was shown to be involved in manganese and ferrous iron transport from the periplasm to the cytoplasm $(116,121,122)$. The ability of the SitABCD transport system to transport manganese might enhance resistance to oxidative stress and survival in extraintestinal tissues (123).

In APEC strains, sit genes are highly associated with virulence in 1-day-old chicks, and there is a prevalence of this system in virulent isolates when compared with fecal commensals $(\underline{40}, \underline{123})$. Interestingly, although sit genes are also found on the chromosome of some E. coli strains, the sit $A B C D$ operon in APEC strains is mainly plasmid-encoded (124).

\section{EitABCD System}

An additional $A B C$ transport system, Eit $A B C D$, has been found on pAPEC-O2-ColV and on pAPEC-O1-ColBM plasmids $(28, \underline{30})$. EitABCD is similar at the protein level, with an iron transport system of the plant pathogen Pseudomonas syringae (30). The functionality of this $\mathrm{ABC}$ system in iron uptake has yet to be determined. The homology between the Eit and Sit $\mathrm{ABC}$ transporters present on the pAPEC-O2-ColV plasmid is very low, and the functional genes also differ in the order within the clusters (Fig. 1). While the SitABCD system has been shown to be a metal ion transporter, EitABCD shares similarity with other $\mathrm{ABC}$ transporters involved in siderophore transport.

Other ColV plasmids sequenced so far do not harbor the eit $A B C D$ cluster, while this system is found on nonColV repFIB and repFII plasmids (29). Interestingly, these two replicons are those harbored by several ColV plasmids. The repFIB plasmids, found in $97 \%$ of 229 Chronobacter spp., emerging neonatal pathogens, harbor the Eit system. The eit gene arrangement in the Chronobacter plasmids, pESA3 and pCTU1, differs from the typical single-operon eit $A B C D$ found in several enteric pathogens. In these Chronobacter plasmids the genes are organized as two divergent operons, eit $A B C$ and eitD (64). Expression of these eit operons does not seem to be regulated by iron despite the presence of putative Fur boxes upstream of the eit $A$ and eitD genes (65). IncFII plasmids harboring the eit $A B C D$ cluster are instead found in APEC and Klebsiella strains (125-127).
The prevalence of eit genes among ExPEC of human and avian origin is low, which could indicate a recent acquisition of these genes by ExPEC strains (126).

\section{Temperature-Sensitive Hemagglutinin Tsh}

The Tsh protein of APEC strain $\chi 7122$ was characterized as a hemagglutinin with a proteolytic domain expressed at lower temperatures (128). This hemagglutinin was the first identified member of an expanding subclass of the IgA protease family of autotransporters present in Shigella and numerous pathotypes of E. coli (129). Autotransporters consist of three functional domains: a secdependent amino-terminal leader sequence, a passenger domain, and an outer membrane-associated carboxyterminal $\beta$-barrel domain (see Fig. 1) (129). The latter domain mediates secretion of the passenger domain, the extracellular or surface-secreted mature protein. The $106-\mathrm{kDa}$ passenger domain of Tsh contains a serine protease motif whose function could not be demonstrated (130). Tsh is almost identical to Hbp (only two amino acid differences), an autotransporter from an E. coli clinical isolate from a wound infection. Hbp was shown to specifically degrade human hemoglobin and bind heme and it was proposed to be part of a hemophoredependent heme acquisition system (131). A similar role was speculated for the other members of the Tsh family (131).

The tsh genes as well as the $h b p$ genes are often located on plasmids $(131,132)$. In a screening study of 300 avian E. coli isolates, the tsh gene was more prevalent in high-lethality isolates, where it was always plasmid-encoded (132). In the same study, it was shown that the majority of the plasmids harboring tsh were of the ColV-type, while a restricted minority was not (132). The association of the $t s h$ gene with large plasmids containing the colicin $\mathrm{V}$ gene cluster is confirmed by the growing number of complete sequences of ColV plasmids, although not all of the ColV plasmids harbor the $t$ sh gene (117). The $t$ sh gene has also been found within PAI III of UPEC strain 536 together with the iro cluster and a putative heme receptor (98). The different distribution of $t s h$ compared to the widespread aerobactin system supports their association with virulence of APEC strains; it is worth noting that although the $t s h$ gene is associated with high lethality, the highest level of virulence seems to require the aerobactin siderophore and not Tsh (9). In agreement with this is the minor role of iron acquisition through heme during infection, which is confirmed by studies with mutant strains in a chicken infection model (91). On the other hand, Tsh might have a role in the air sacs, as supported by infec- 
tion studies and expression of the gene in the air sacs (90, 132). Other iron uptake systems, such as aerobactin and salmochelin siderophores, might be more important in deeper tissues (90).

\section{Hemolysin}

Another gene involved in iron uptake and associated with ColV plasmids is the $h l y F$ gene (Fig. 1). This gene has been found in the majority of the APEC ColV plasmids and in several ExPEC strains (29, 31, 133). The $h l y F$ gene, its product $\mathrm{HlyF}$, and its mode of action still need to be characterized. HlyF has hemolytic activity, but its amino acid sequence shows no significant homology to HlyA, the RTX hemolysin of several E. coli pathotypes, or to HlyE, a more recently identified hemolysin distinct from HlyA (134-137). Besides HlyF, the HlyA hemolysin is associated with plasmids. In fact, while the blyCABD operon is found on the chromosome in UPEC strains, large plasmids harbor hemolysin clusters in human enterohemorrhagic E. coli (EHEC) strains and enterotoxigenic, shigatoxigenic, and enteropathogenic E. coli strains isolated from animals (138-141). The HlyA hemolysin found in EHEC, the enterohemolysin, is distinct from the HlyA hemolysin found in the other E. coli pathogroups, the $\alpha$-hemolysin $(134,137)$. Plasmids of EHEC strains are, like ColV plasmids, F-like plasmids, and they share a similar backbone for what concerns origins of replication and transfer region, although the majority of EHEC plasmids are transferdefective $(29,142,143)$. On the other hand, plasmids harboring the genetic determinants for production of $\alpha$ hemolysin were found to be heterogeneous also in their incompatibility group $(\underline{144}, \underline{145})$. DNA hybridization experiments indicate that plasmid-encoded $\alpha$-hemolysin and enterohemolysin have evolved separately in EHEC and enteropathogenic strains, although they might exert the same function $(141,146)$. On the other hand, the high similarity at the sequence level of $\alpha$-hemolysin operons present on plasmids in enterotoxigenic, shigatoxigenic, and enteropathogenic strains indicates a common origin for these genes $(\underline{138}, 146)$.

The blyA gene encodes the pro-hemolysin that is converted to its active form by the product of the blyC gene by transfer of two fatty-acyl residues onto proHlyA. A type-I secretory complex comprising the ATPbinding cassette $\mathrm{HlyB}$, the membrane-fusion protein $\mathrm{HlyD}$, and the outer-membrane protein TolC secrete the active HlyA as well as the pro-HlyA. HlyA interaction with the target cell membrane occurs in two steps: the $\alpha$-hemolysin absorbs onto the membrane in a reversible manner that is followed by irreversible insertion within the membrane. Once HlyA is inserted in the membrane, oligomerization occurs, leading to pore formation and cell lysis (147).

The role of hemolysins in iron uptake is still under debate. It has been proposed that secretion of hemolysins and cytolysins can quickly increase the local concentration of free heme and hemoglobin. This proposal is supported by indirect evidence such as hemolysin expression often repressed by iron and the presence of heme transport systems in strains with hemolytic activity $(134,148,149)$. The presence of $b l y F$ together with the tsh gene on the same plasmid further supports the possibility of their products acting as a hemophore-dependent heme acquisition system in combination with a chromosomally encoded heme receptor, such as ChuA. Besides colocalization in some cases, hly genes and $c h u A$ share a positive regulator, as can be expected for genes that function in the same system $(\underline{147}, \underline{150})$.

\section{Heterogeneity of ColV Determinants}

As proposed by Waters and Crosa (27), a "constant" and a "variable" region, together spanning a 94-kb cluster of putative virulence genes, can be distinguished within the ColV PAI. The constant region contains the repFIB replicon, the aerobactin operon, the Sit iron and manganese transport system, a putative outer membrane protease gene, ompT, the hemolysin gene, $h l y F$, a novel $\mathrm{ABC}$ transport system known as Ets, the salmochelin siderophore system, and iss that encodes serum resistance (30). The temperature-sensitive hemagglutinin gene $t s h$ and another novel transport system known as Eit are part of the variable portion, as they are less frequently associated with ColV plasmids than are the genes in the constant region (29). The divide between the two regions appears to be within the colV operon, with a clear higher cooccurrence of genes within the constant region (about $60 \%$ ) than the $26 \%$ for genes of the variable region $(\underline{30})$.

From the increasing number of large plasmid complete sequences, a remarkable high nucleotide similarity $(>95 \%)$ in the common regions of ColV plasmids is becoming evident. This suggests that ColV plasmids have evolved by adding and deleting large blocks of DNA, and these rearrangements are most likely the product of IS-mediated recombination events that affect the core as well as the noncore regions. As a consequence, a great heterogeneity in gene content is found within the ColV plasmid group (29).

As a result of frequent recombination events, widespread diversity in the noncore components is found in the sequenced plasmids, none of which are identical to 
each other with regard to gene content. In extreme cases, plasmids can lack the entire variable region. There is also an example of a strain harboring the constant region on one plasmid and part of the variable region (the eit operon) on another (31, 51, 126).

IS-mediated recombination events may also account for the occurrence of some of the ColV plasmid components on non-ColV plasmids or on the chromosome of E. coli, Shigella, Salmonella, and possibly other bacterial strains. It is not yet clear if this transfer of genetic information proceeds from plasmid to chromosome or from chromosome to plasmid. The fact that in S. flexneri PAI SHI-2 harboring the aerobactin system also encodes immunity to colicins I and V suggests that the aerobactin genes found in SHI-2 originated from a ColV plasmid (73). In contrast, it has been proposed that ColV plasmids function as transposon traps for virulence-related determinants, pointing to a flow of genetic information to the plasmid rather than from it (131).

Aerobactin is also found on Klebsiella high-molecularweight plasmids, and the presence of this system has been associated with virulent isolates (75). Although the system found in Klebsiella plasmids shows homology with the ColV genes, a certain degree of divergence and the absence of IS1 insertion sequences downstream of the genes in Klebsiella might indicate different origins of the two systems (75).

Genes coding for aerobactin, salmochelin, and the Sit systems have been found on non-ColV plasmids of E. coli, Salmonella, and Klebsiella that are often associated with antibiotic resistance genes $(\underline{38}, \underline{51}, \underline{62}, \underline{75}$, $102,151)$. Occurrence of resistance determinants on ColV plasmids from different bacterial hosts has also been reported $(29,41,42)$. The high degree of conservation of these resistance elements and their presence on unrelated plasmids suggest a shared horizontal resistance gene pool available to bacteria from different environments (152). The association of drug resistance determinants with virulence plasmids is quite worrisome since it may enhance pathogenicity in environments where antibiotics are used.

\section{pJM1-TYPE PLASMIDS}

Plasmids of the pJM1 type are only found in the bacterium $V$. anguillarum, and more specifically, only in serotype $\mathrm{O} 1$ strains of this bacterium. V. anguillarum is the causative agent of vibriosis in fish, a highly fatal hemorrhagic septicemic disease (153). Several studies showed that $V$. anguillarum strains harboring pJM1 have a reduced infectivity in the absence of the plasmid
(153-158). Plasmids of the pJM1 family range between 65 and $70 \mathrm{~kb}$, and their difference in size is mainly due to the number of insertion sequences present. Plasmids in this group are highly similar, as shown in independent studies using restriction length polymorphism, where only a few patterns were identified among numerous different isolates from the United States, Japan, Spain, and Denmark (159-162).

To date, three complete annotated sequences of pJM1type plasmids are available: the pJM1 plasmid from $V$. anguillarum 775 (65,009 nucleotides) and pEIB1 from $V$. anguillarum MVM425 and plasmid M3 from $V$. anguillarum M3, which are both 66,164 nucleotides $(161,163,164)$. These plasmids are highly conserved and differ only in few nucleotides over the $65 \mathrm{~kb}$ they have in common.

The vast majority of the genes encoded on the pJM1type plasmids are involved in iron uptake, either directly or indirectly (Fig. 2). The remaining genes code for proteins involved in plasmid replication, insertion sequences, and those for which no function can be assigned based on their homology $(\underline{161}, \underline{163}, \underline{164})$.

\section{Replication and Transfer}

The origin of replication was first identified on the pJM1 plasmid and later was further characterized on pJM1 and the pJM1-type plasmid pEIB1 (164-166). A 1,400bp Sau3A fragment from pEIB1 was identified that can replicate in E. coli and V. anguillarum as well as in other Vibrio species such as Vibrio alginolyticus. The region contains replication features such as DnaA binding sites and inverted repeats (164). Recombinant plasmids consisting of different pJM1 fragments containing this origin of replication (ori1) and a resistance marker could replicate in a plasmid-less derivative of $V$. anguillarum 775 but resulted in different copy numbers (166). However, in E. coli all fragments tested had similar copy numbers, in all instances higher than in V. anguillarum. Hence, the pJM1 plasmid ori1 has some kind of copy number control that only functions in $V$. anguillarum (166). In the same study, it was shown that DnaA is not required for replication of $\mathrm{pJM} 1$, in contrast with the results obtained with the pEIB1 plasmid $(164,166)$. Interestingly, deletion of ori1 resulted in a pJM1 derivative still able to replicate, indicating the presence of a second origin of replication (ori2). Ori2 is located at ORF25 (Fig. 2), but unlike ori1, it cannot replicate in E. coli $(164,166)$.

Genes such as those encoding DnaB, DnaC, and DnaG, which are needed for DNA replication, are provided by the chromosome as well as a polymerase since 
Di Lorenzo and Stork

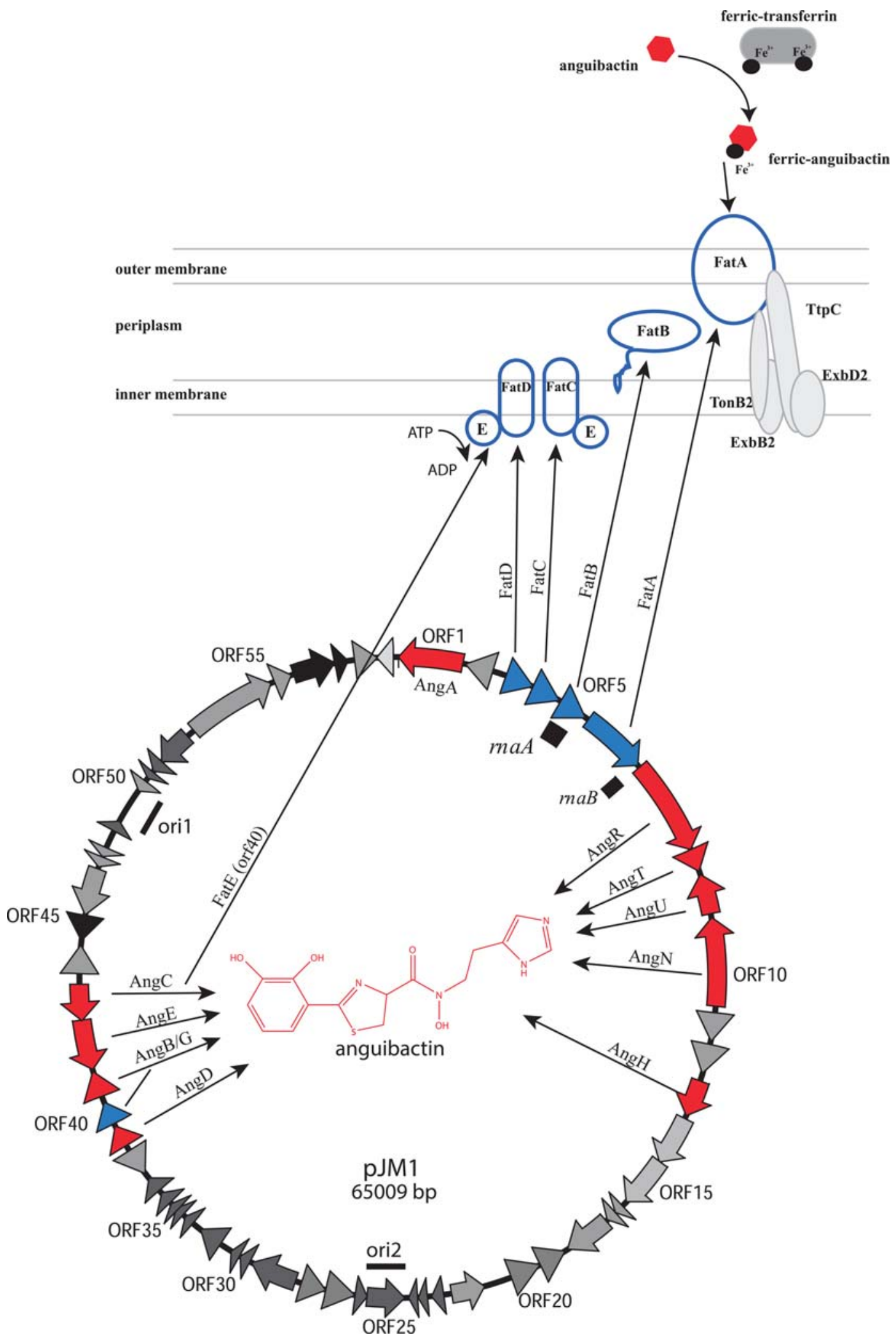

FIGURE 2 Schematic representation of the pJM1 plasmid showing all open reading frames, the structure of anguibactin, and the transport proteins in the membranes. Genes that are involved in siderophore synthesis are shown in red; those involved in transport are blue. Black boxes indicate the location of the antisense RNAs. The shaded proteins in transport are chromosomally encoded. Location of the origins of replication is indicated by a black line. doi:10.1128/microbiolspec.PLAS-0030-2014.f2 
no polymerase is encoded by the plasmid $(161,166)$. The incompatibility group for both replicons is unknown, and no homology with known origins of replication has been found. Ori1 is compatible with plasmids such as pUC18 (pMB1), pKA3 (pSC101), and p15A in E. coli (164). On the other hand, conjugation into V. anguillarum of some plasmids was prevented by the presence of plasmids of the pJM1 group (167). Singer and colleagues hypothesized that the lack of transconjugants in their study resulted from the presence of a restrictionmodification system on pJM1-type plasmids (167). From the several complete sequences of pJM1-type plasmids available, it is evident that no restriction-modification system is present. An alternative explanation for the lack of transconjugants could be incompatibility between the replicon of the tested plasmids and one of the origins of replication of pJM1. The fact that ultraviolet treatment restored plasmid introduction by conjugation could then be explained by a mutation in the incompatible origin.

No transfer genes have been identified in the available complete sequences of pJM1-type plasmids (161, $163,164)$. The lack of tra genes might explain the restriction of these plasmids to serotype O1 strains of V. anguillarum (168).

\section{Iron Uptake System}

$V$. anguillarum 775 , the prototype serogroup O1 strain, secretes a siderophore, a low-molecular-weight highaffinity iron-binding compound (169). This siderophore, called anguibactin, is linked to the plasmid, since siderophore production is abolished in a strain lacking the plasmid $(157,170,171)$. In addition, the proteins needed for the transport of the ferric-siderophore across the membranes are also located on the plasmid (170-172). Fish infectivity studies showed that both the siderophore and the transport system are needed for infection. In strains harboring only the transport genes, establishment of an infection and replication in the bloodstream can occur only in the presence of strains producing the siderophore (158).

\section{Anguibactin Biosynthesis}

The siderophore anguibactin is produced via a nonribosomal peptide synthetase mechanism. Nonribosomal peptide synthetases (NRPSs) catalyze peptide bond formation in the absence of an RNA template (10). Via this mechanism non-amino acid substrates, such as carboxylic acid, can also be incorporated. NRPSs are multimodular, and the order of the modules determines the order of the amino/carboxilic acids in the final product. A minimal NRPS consists of an adenylation domain (A) to activate the substrate, a peptidyl or aryl carrier domain (PCP/ArCP) to tether the activated substrate, and a condensation domain $(\mathrm{C})$ to form a peptide bond between two activated substrates (173). In addition, there are domains that can modify the substrates, bringing even more variability to the peptide structure. In the case of antibiotic synthesis these modules are often located on one or two large polypeptides, while in the case of siderophore biosynthesis these modules are scattered over multiple proteins.

The building blocks of anguibactin are $N$-hydroxyhistamine, L-cysteine, and the carboxylic acid dihydroxy benzoic acid (DHBA) (169). All enzymes needed for the production of anguibactin are encoded on the pJM1and pJM1-type plasmids (Fig. 2) (161, 163, 164). Genes for the biosynthesis of the anguibactin precursor DHBA, ang $B$ and $a n g C$, are also carried by the plasmid, with the exception of angA, for which only a truncated nonfunctional gene is present on the plasmid. As a consequence, for DHBA production, a functional AngA protein must be encoded on the chromosome. In some $V$. anguillarum strains, the chromosomal angA gene is present in a cluster with the other DHBA biosynthetic genes since these strains still produce DHBA when cured from the plasmid $(174,175)$. In the case of $V$. anguillarum 531A, curing of the plasmid abolishes DHBA production, pointing to an incomplete chromosomally encoded DHBA cluster (176). The plasmid also carries the genes for the synthesis of $\mathrm{N}$-hydroxyhistamine from histidine. The angH and the ang $U$ genes encode, respectively, a histine decarboxylase and a histamine monooxygenase. Mutations in angH or curing of the plasmid abolished histamine production, indicating that there are no chromosomal copies of this gene $(177, \underline{178})$.

The synthesis of anguibactin begins with activation of DHBA by the adenylation domain of AngE. Activated DHBA is then tethered to the ArCP domain of AngG to further continue its assembly in the anguibactin molecule $(\underline{100}, 175,176,179)$. The ang $G$ gene is transcribed from the same promoter as angB and can be found in one polypeptide with AngB but also as a separate polypeptide (176). Tethering of activated substrates to ArCP and PCP domains of NRPSs occurs at a phosphopantetheinyl arm. This arm is posttranslationally added by AngD to a conserved serine residue within the ArCP and PCP domains (180).

L-cysteine is activated by the A domain of AngR and tethered to the PCP domain of AngM (181). The first amide bond forms between the DHBA tethered onto the ArCP domain of AngB and the amino group of the cysteine loaded on the PCP domain of AngM. This step 
is followed by cyclodehydration of cysteine to a thiazoline ring. Both steps are mediated by the Cy domains of AngN (182). The final product, anguibactin, is then released by transfer of the dihydroxyphenyl thiazolyl intermediate from the PCP domain of AngM to the secondary amine of hydroxyhistamine in a reaction that requires the activity of the C domain of AngM (181). DHBA and histamine are dedicated metabolites for the synthesis of anguibactin, while L-cysteine is the only proteinogenic amino acid of the siderophore. Anguibactin has a quite compact structure, with three different chemical groups, all possessing iron-chelating properties (183). Furthermore, anguibactin belongs to the hydroxamate as well as the catecholate siderophores due to the presence of both functional groups.

\section{Transport}

The uptake of anguibactin (Fig. 2) initiates with the binding of the ferric-siderophore to the outer membrane receptor FatA (184-187). FatA is a typical outer membrane receptor containing 22 antiparallel beta strands that form the barrel. It has a plug domain that blocks the open channel and extracellular loops that are needed for the initial binding to the siderophore (187). FatA then facilitates the transport over the outer membrane via an energy-dependent mechanism that requires the TonB system $(16,188)$. The genes of the TonB system are encoded on the chromosome $(16,188)$. V. anguillarum has two TonB systems, and both can transduce the energy to FatA. However, one of the two systems is much more efficient in the transport of anguibactin and requires an additional protein, TtpC, in the complex $(16,188)$. Once in the periplasm, ferric-anguibactin is bound by FatB, a lipoprotein anchored to the outer leaflet of the inner membrane (189-191). Anchoring of the periplasmic binding protein is not essential since transport still occurs when the lipid moiety is removed (191). However, transport is abolished in the absence of the FatB protein. From the periplasmic binding protein $\mathrm{FatB}$, the ferric-siderophore is transferred to FatC and FatD. FatC and FatD form a typical ABC transporter and are both essential for internalization of anguibactin (191). The energy for this internalization is provided by the ATPase FatE, which is encoded by a gene within the cluster for DHBA at a different locus than the other transport genes. A FatE mutant was still proficient in the uptake of the siderophore, while a double FvtE and FatE strain was not capable of internalizing the siderophore (192). The FvtE protein is involved in the uptake of vanchrobactin, a chromosomally encoded siderophore found in many $V$. anguillarum strains (193, 194). In strains harboring pJM1-type plasmids, genes of the vanchrobactin system, including the $f v t E$ gene, are present on the chromosome, but this system is inactivated by an insertion in one of the vanchrobactin biosynthesis genes (195).

\section{Regulation}

The best-studied region of pJM1-type plasmids is the socalled iron transport and biosynthesis (ITB) operon. This operon consists of six genes transcribed from a single promoter $(161,170)$. The first four genes, fat $D, C, B$, and $A$, are involved in iron transport, and the last two, angR and ang $T$, in siderophore biosynthesis-hence the name.

Three plasmid-encoded factors act as positive regulators enhancing the expression of the ITB operon. One of these factors is the AngR protein, which is needed for the synthesis of the siderophore and encoded by a gene that is part of the ITB operon $(196,197)$. It was shown that the AngR protein enhances the expression of the ITB operon by 2.5 -fold (198). The AngR polypeptide contains predicted helix-turn-helix and leucine zipper motifs common to DNA binding proteins and transcriptional regulators (199). In addition to AngR, another factor, called TAF, enhances gene expression of the ITB operon by about 4-fold (198). TAF stands for trans acting factor because it is located outside the ITB operon. If AngR- and TAF-positive regulation are combined, a 23-fold increase in expression is seen, indicating some synergistic/cooperative action between the two regulators (198). Besides the ITB operon promoter, AngR and TAF also regulate the expression of the angN gene (182).

The third factor is the anguibactin siderophore itself, which acts as a positive regulator of the ITB operon promoter (23).

Like most iron uptake systems, the iron uptake genes on the pJM1-type plasmid are regulated by the chromosomally encoded protein Fur (200-203). Fur binds to two loci upstream of the ITB operon promoter and bends the DNA by dimerization of the proteins at the two loci (202). Under iron-limiting conditions, the Fur protein dimer loses its iron and the dimer falls apart, abolishing DNA binding and thereby relieving repression (202). The regulation by Fur extends to other genes involved in anguibactin biosynthesis such as angM and $\operatorname{angN}(\underline{181}, 182)$.

Besides this general regulator, the plasmid itself encodes two antisense RNAs that act as negative regulators of gene expression.

The first antisense RNA, RNA $\alpha$, was discovered on the opposite strand of the fatB gene $(\underline{203}, 204)$. Tran- 
scription of this antisense RNA requires the Fur protein, and under iron-replete conditions RNA $\alpha$ negatively regulates the $f a t A$ and $f a t B$ transcripts (203).

The second antisense RNA is located within the ITB operon, complementary to the fat $A$ and ang $R$ genes (205). This RNA, called RNA $\beta$, controls the differential gene expression between the transport and the biosynthesis genes within the ITB operon (205). In fact, although they are transcribed from the same promoter, the levels of fat $A$ and angR differ by 17-fold (206). The difference is due to transcription termination between the fat $A$ and angR genes that is mediated by RNA $\beta$ $(206,207)$. It has been proposed that RNA $\beta$ binds to the newly transcribed message, destabilizing the transcription complex, which leads to transcription termination (206). It is unknown if the two antisense RNAs control gene expression at loci other than their sense transcripts.

\section{Heterogeneity of the pJM1 Determinants}

As already mentioned, the pJM1-type plasmids are highly similar. The six restriction length polymorphism patterns identified differ mainly in the number of insertion sequences (the ISV-A2 elements) present $(161,162)$. However, there are some minor changes at the nucleotide level that have major impacts. For instance, the DNA sequence of the ang $R$ gene differs by a single nucleotide between pJM1 plasmid from V. anguillarum 775 and the pJM1-type plasmid pJHC1 from V. anguillarum 531A $(208,209)$. Where a histidine is present at position 267 in the AngR protein encoded by the pJM1 plasmid, an asparagine is present in the AngR protein of pJHC1 (208). This nucleotide change results in higher anguibactin production in the $531 \mathrm{~A}$ strain. The $\mathrm{LD}_{50}$ values are similar for both bacteria, making it unclear what is the benefit for the bacterium to produce increased levels of siderophore (199).

When the three sequenced pJM1-type plasmids are aligned, only 16 nucleotide changes are revealed. Besides these single-nucleotide polymorphisms, the pJM1 plasmid has an extra 359-nucleotide HindIII fragment in the angN gene. The absence of this fragment in the M3 and pEIB1 plasmids results in the deletion of one of the two cyclization domains in AngN. Site-directed mutagenesis in the angN gene of pJM1 showed that at least one of the two Cy domains of AngN must be functional for anguibactin biosynthesis (182). However, one missing $\mathrm{Cy}$ domain reduced the production of anguibactin. The anguibactin-producing phenotypes of M3 and pEIB1 are not known. It would be of interest to see the effect of the deletion in AngN on anguibactin production, especially since the M3 plasmid and pEIB1 carry the point mutation in the angR gene that causes increased production of anguibactin in strain 531A. Another major change is the presence of an additional ISV-A2 element in the pEIB1 and M3 plasmids $(163,164)$.

While pJM1-type plasmids are found only in serogroup $\mathrm{O} 1$ strains, some genes are found outside this specific reservoir. The fat $A$ and $f a t D$ genes have been identified on the chromosome of serotype O2a and NT4 $V$. anguillarum strains by PCR and DNA sequencing. These strains did not contain the angR gene (210).

A more striking discovery was the identification of an $\operatorname{ang} R$ gene homolog in a whole-genome sequence of Vibrio harveyi (211). Further detailed analysis revealed that the chromosome of this bacterium encodes the complete ITB operon including the upstream angM gene and downstream genes angH, ang $U$, and $a n g N$. In the case of $V$. harveyi the ang $B G$ gene is located in proximity to the cluster, while on the pJM1 plasmids the two clusters are located in noncontiguous regions (211).

\section{CONCLUDING REMARKS}

The first identified plasmid harboring an iron uptake system was a ColV plasmid, which was followed soon after by the discovery of pJM1 $(\underline{58}, 157)$. Plasmid types encoding iron uptake systems are rare, and despite their concomitant discovery, ColV- and pJM1-type plasmids are quite different. The most striking difference is the presence of numerous iron and non-iron-related determinants on ColV against the single iron uptake system encoded on pJM1. The anguibactin system is the only plasmid trait identified so far on pJM1-type plasmids. Furthermore, the latter are restricted to serotype O1 $V$. anguillarum strains, while the ColV plasmids are more widespread even across genera (29, 41, 42, 51, 152). The restriction of pJM1-type plasmids could be the result of their inability to be transferred, whereas the ColV plasmids are conjugative. As a consequence, it is not surprising that, over 50 years after the first description of a plasmid-linked colicin V, ColV plasmids are still identified in isolates from human and animal infections $(45,117,212,213)$. Another important difference between the ColV- and pJM1-type plasmids is the recent association of the former with antibioticresistance determinants. Non-ColV plasmids harboring multidrug resistance and ColV virulence factors have been described in the past, but recently, a ColV plasmid encoding antibiotic resistance has been identified (212). The lack of such determinants on pJM1-type plasmids could be a consequence of lower levels of antibiotics in environments where $V$. anguillarum is present. 
Alternatively, the limited interaction with other plasmids harboring resistance genes could have prevented the spread of multidrug resistance on pJM1-type plasmids.

The evolution of both plasmid types has most likely proceeded by the addition and deletion of large blocks of DNA. Entire systems are either absent or highly similar at the nucleotide level when present (214). Within this mosaic structure the iron uptake systems present are highly conserved across the members of the ColV and pJM1 types.

\section{ACKNOWLEDGMENTS}

We thank Jorge H. Crosa, who passed away too soon. He not only formed the basis of both of our careers, but also of the plasmidmediated iron uptake research.

Publication 5716 of the Netherlands Institute of Ecology (NIOO-KNAW).

Conflicts of interest: We disclose no conflicts.

\section{REFERENCES}

1. Galaris D, Pantopoulos K. 2008. Oxidative stress and iron homeostasis: mechanistic and health aspects. Crit Rev Clin Lab Sci 45:1-23.

2. Crosa JH, Mey AR, Payne SM. 2004. Iron Transport in Bacteria. ASM Press, Washington, DC.

3. Weinberg ED. 1993. The development of awareness of iron-withholding defense. Perspect Biol Med 36:215-221.

4. Skaar EP. 2010. The battle for iron between bacterial pathogens and their vertebrate hosts. PLoS Pathog 6:e1000949. doi:10.1371/journal .ppat.1000949.

5. Porcheron G, Garenaux A, Proulx J, Sabri M, Dozois CM. 2013. Iron, copper, zinc, and manganese transport and regulation in pathogenic Enterobacteria: correlations between strains, site of infection and the relative importance of the different metal transport systems for virulence. Front Cell Infect Microbiol 3:90.

6. Noinaj N, Buchanan SK, Cornelissen CN. 2012. The transferrin-iron import system from pathogenic Neisseria species. Mol Microbiol 86:246257.

7. Noinaj N, Cornelissen CN, Buchanan SK. 2013. Structural insight into the lactoferrin receptors from pathogenic Neisseria. J Struct Biol 184:8392.

8. Runyen-Janecky LJ. 2013. Role and regulation of heme iron acquisition in Gram-negative pathogens. Front Cell Infect Microbiol 3:55.

9. Raymond KN, Dertz EA. 2004. Biochemical and physical properties of siderophores, p 3-17. In Crosa JH, Mey AR, Payne SM (ed), Iron Transport in Bacteria. ASM Press, Washington, DC.

10. Crosa JH, Walsh CT. 2002. Genetics and assembly line enzymology of siderophore biosynthesis in bacteria. Microbiol Mol Biol Rev 66:223-249.

11. Crosa JH. 1989. Genetics and molecular biology of siderophoremediated iron transport in bacteria. Microbiol Rev 53:517-530.

12. Ratledge C, Dover LG. 2000. Iron metabolism in pathogenic bacteria. Annu Rev Microbiol 54:881-941.

13. Chakraborty R, Storey E, van der Helm D. 2007. Molecular mechanism of ferricsiderophore passage through the outer membrane receptor proteins of Escherichia coli. Biometals 20:263-274.

14. Kuehl CJ, Crosa JH. 2010. The TonB energy transduction systems in Vibrio species. Future Microbiol 5:1403-1412.

15. Kustusch RJ, Kuehl CJ, Crosa JH. 2012. The ttpC gene is contained in two of three TonB systems in the human pathogen Vibrio vulnificus, but only one is active in iron transport and virulence. J Bacteriol 194:32503259.
16. Stork M, Otto BR, Crosa JH. 2007. A novel protein, TtpC, is a required component of the TonB2 complex for specific iron transport in the pathogens Vibrio anguillarum and Vibrio cholerae. J Bacteriol 189:1803-1815. 17. Postle K, Larsen RA. 2007. TonB-dependent energy transduction between outer and cytoplasmic membranes. Biometals 20:453-465.

18. Krewulak KD, Peacock RS, Vogel HJ. 2004. Perisplasmic binding proteins involved in bacterial iron uptake, p 113-129. In Crosa JH, Mey AR, Payne SM (ed), Iron Transport in Bacteria. ASM Press, Washington, DC.

19. Andrews SC, Robinson AK, Rodriguez-Quinones F. 2003. Bacterial iron homeostasis. FEMS Microbiol Rev 27:215-237.

20. Bagg A, Neilands JB. 1987. Ferric uptake regulation protein acts as a repressor, employing iron (II) as a cofactor to bind the operator of an iron transport operon in Escherichia coli. Biochemistry 26:5471-5477.

21. Hantke K. 1981. Regulation of ferric iron transport in Escherichia coli K12: isolation of a constitutive mutant. Mol Gen Genet 182:288-292. 22. Troxell B, Hassan HM. 2013. Transcriptional regulation by ferric uptake regulator (Fur) in pathogenic bacteria. Front Cell Infect Microbiol 3:59. 23. Chen Q, Wertheimer AM, Tolmasky ME, Crosa JH. 1996. The AngR protein and the siderophore anguibactin positively regulate the expression of iron-transport genes in Vibrio anguillarum. Mol Microbiol 22:127-134.

24. Mahren S, Braun V. 2003. The FecI extracytoplasmic-function sigma factor of Escherichia coli interacts with the beta' subunit of RNA polymerase. J Bacteriol 185:1796-1802.

25. Crosa JH, Actis LA, Mitoma Y, Perez-Casal J, Tolmasky ME, Valvano MA. 1985. Plasmid-mediated iron sequestering systems in pathogenic strains of Vibrio anguillarum and Escherichia coli. Basic Life Sci 30:759774.

26. Walter MA, Bindereif A, Neilands JB, Crosa JH. 1984. Lack of homology between the iron transport regions of two virulence-linked bacterial plasmids. Infect Immun 43:765-767.

27. Waters VL, Crosa JH. 1991. Colicin V virulence plasmids. Microbiol Rev 55:437-450.

28. Johnson TJ, Johnson SJ, Nolan LK. 2006. Complete DNA sequence of a ColBM plasmid from avian pathogenic Escherichia coli suggests that it evolved from closely related ColV virulence plasmids. J Bacteriol 188:5975-5983.

29. Johnson TJ, Nolan LK. 2009. Pathogenomics of the virulence plasmids of Escherichia coli. Microbiol Mol Biol Rev 73:750-774.

30. Johnson TJ, Siek KE, Johnson SJ, Nolan LK. 2006. DNA sequence of a ColV plasmid and prevalence of selected plasmid-encoded virulence genes among avian Escherichia coli strains. J Bacteriol 188:745-758.

31. Mellata M, Touchman JW, Curtiss R. 2009. Full sequence and comparative analysis of the plasmid pAPEC- 1 of avian pathogenic E. coli $\chi 7122$ (O78:K80:H9). PLoS One 4:e4232. doi:10.1371/journal.pone.0004232.

32. Perez-Casal JF, Crosa JH. 1987. Novel incompatibility and partition loci for the REPI replication region of plasmid ColV-K30. J Bacteriol 169: 5078-5086.

33. Perez-Casal JF, Gammie AE, Crosa JH. 1989. Nucleotide sequence analysis and expression of the minimum REPI replication region and incompatibility determinants of pColV-K30. J Bacteriol 171:2195-2201. 34. Gammie AE, Crosa JH. 1991. Roles of DNA adenine methylation in controlling replication of the REPI replicon of plasmid pColV-K30. Mol Microbiol 5:495-503.

35. Gammie AE, Crosa JH. 1991. Co-operative autoregulation of a replication protein gene. Mol Microbiol 5:3015-3023.

36. Gammie AE, Tolmasky ME, Crosa JH. 1993. Functional characterization of a replication initiator protein. J Bacteriol 175:3563-3569.

37. Waters VL, Crosa JH. 1986. DNA environment of the aerobactin iron uptake system genes in prototypic ColV plasmids. J Bacteriol 167:647-654. 38. Colonna B, Nicoletti M, Visca P, Casalino M, Valenti P, Maimone F. 1985. Composite IS1 elements encoding hydroxamate-mediated iron uptake in FIme plasmids from epidemic Salmonella spp. J Bacteriol 162:307-316. 
39. Fernandez-Beros ME, Kissel V, Lior H, Cabello FC. 1990. Virulencerelated genes in ColV plasmids of Escherichia coli isolated from human blood and intestines. J Clin Microbiol 28:742-746.

40. Rodriguez-Siek KE, Giddings CW, Doetkott C, Johnson TJ, Nolan LK. 2005. Characterizing the APEC pathotype. Vet Res 36:241-256.

41. Fricke WF, McDermott PF, Mammel MK, Zhao S, Johnson TJ, Rasko DA, Fedorka-Cray PJ, Pedroso A, Whichard JM, Leclerc JE, White DG, Cebula TA, Ravel J. 2009. Antimicrobial resistance-conferring plasmids with similarity to virulence plasmids from avian pathogenic Escherichia coli strains in Salmonella enterica serovar Kentucky isolates from poultry. Appl Environ Microbiol 75:5963-5971.

42. Johnson TJ, Thorsness JL, Anderson CP, Lynne AM, Foley SL, Han J, Fricke WF, McDermott PF, White DG, Khatri M, Stell AL, Flores C, Singer RS. 2010. Horizontal gene transfer of a ColV plasmid has resulted in a dominant avian clonal type of Salmonella enterica serovar Kentucky. PLoS One 5:e15524. doi:10.1371/journal.pone.0015524.

43. Gratia A. 1925. Sur un remarquable exemple d'antagisme entre deux souches de collibacille. Crit Rev Soc Biol 93:1041-1042.

44. MacFarren AC, Clowes RC. 1967. A comparative study of two F-like colicin factors, ColV2 and ColV3, in Escherichia coli K-12. J Bacteriol 94:365-377.

45. Nagel De Zwaig R. 1966. Association between colicinogenic and fertility factors. Genetics 55:381-390.

46. Gilson L, Mahanty HK, Kolter R. 1987. Four plasmid genes are required for colicin $\mathrm{V}$ synthesis, export, and immunity. J Bacteriol 169: 2466-2470.

47. Gordon DM, O'Brien CL. 2006. Bacteriocin diversity and the frequency of multiple bacteriocin production in Escherichia coli. Microbiology 152:3239-3244.

48. Yang CC, Konisky J. 1984. Colicin V-treated Escherichia coli does not generate membrane potential. J Bacteriol 158:757-759.

49. Cascales E, Buchanan SK, Duche D, Kleanthous C, Lloubes R, Postle K, Riley M, Slatin S, Cavard D. 2007. Colicin biology. Microbiol Mol Biol Rev 71:158-229.

50. Jeziorowski A, Gordon DM. 2007. Evolution of microcin V and colicin Ia plasmids in Escherichia coli. J Bacteriol 189:7045-7052.

51. Peigne C, Bidet $P$, Mahjoub-Messai F, Plainvert C, Barbe V, Medigue C, Frapy E, Nassif X, Denamur E, Bingen E, Bonacorsi S. 2009. The plasmid of Escherichia coli strain S88 (O45:K1:H7) that causes neonatal meningitis is closely related to avian pathogenic E. coli plasmids and is associated with high-level bacteremia in a neonatal rat meningitis model. Infect Immun 77:2272-2284.

52. Chehade H, Braun V. 1988. Iron-regulated synthesis and uptake of colicin V. FEMS Microbiol Lett 52:177-182.

53. Christenson JK, Gordon DM. 2009. Evolution of colicin BM plasmids: the loss of the colicin B activity gene. Microbiology 155:1645-1655.

54. El Ghachi M, Bouhss A, Barreteau H, Touze T, Auger G, Blanot D, Mengin-Lecreulx D. 2006. Colicin M exerts its bacteriolytic effect via enzymatic degradation of undecaprenyl phosphate-linked peptidoglycan precursors. J Biol Chem 281:22761-22772.

55. Braun V, Patzer SI, Hantke K. 2002. Ton-dependent colicins and microcins: modular design and evolution. Biochimie 84:365-380.

56. Quackenbush RL, Falkow S. 1979. Relationship between colicin V activity and virulence in Escherichia coli. Infect Immun 24:562-564.

57. Williams PH, Warner PJ. 1980. ColV plasmid-mediated, colicin $\mathrm{V}$-independent iron uptake system of invasive strains of Escherichia coli. Infect Immun 29:411-416.

58. Williams PH. 1979. Novel iron uptake system specified by ColV plasmids: an important component in the virulence of invasive strains of Escherichia coli. Infect Immun 26:925-932.

59. Gibson F, Magrath DI. 1969. The isolation and characterization of a hydroxamic acid (aerobactin) formed by Aerobacter aerogenes 62-I. Biochim Biophys Acta 192:175-184.
60. McDougall S, Neilands JB. 1984. Plasmid- and chromosome-coded aerobactin synthesis in enteric bacteria: insertion sequences flank operon in plasmid-mediated systems. J Bacteriol 159:300-305.

61. Waters VL, Crosa JH. 1988. Divergence of the aerobactin iron uptake systems encoded by plasmids pColV-K30 in Escherichia coli $\mathrm{K}-12$ and pSMN1 in Aerobacter aerogenes 62-1. J Bacteriol 170:5153-5160.

62. Colonna B, Ranucci L, Fradiani PA, Casalino M, Calconi A, Nicoletti M. 1992. Organization of aerobactin, hemolysin, and antibacterial resistance genes in lactose-negative Escherichia coli strains of serotype O4 isolated from children with diarrhea. Infect Immun 60:5224-5231.

63. Riley PA, Threlfall EJ, Cheasty T, Wooldridge KG, Williams PH, Phillips I. 1993. Occurrence of FIme plasmids in multiple antimicrobialresistant Escherichia coli isolated from urinary tract infection. Epidemiol Infect 110:459-468.

64. Franco AA, Hu L, Grim CJ, Gopinath G, Sathyamoorthy V, Jarvis KG, Lee C, Sadowski J, Kim J, Kothary MH, McCardell BA, Tall BD. 2011. Characterization of putative virulence genes on the related RepFIB plasmids harbored by Cronobacter spp. Appl Environ Microbiol 77:3255-3267.

65. Grim CJ, Kothary MH, Gopinath G, Jarvis KG, Beaubrun JJ, McClelland M, Tall BD, Franco AA. 2012. Identification and characterization of Cronobacter iron acquisition systems. Appl Environ Microbiol 78:6035-6050.

66. Szczepanowski R, Braun S, Riedel V, Schneiker S, Krahn I, Puhler A, Schluter A. 2005. The $120592 \mathrm{bp} \mathrm{IncF}$ plasmid pRSB107 isolated from a sewage-treatment plant encodes nine different antibiotic-resistance determinants, two iron-acquisition systems and other putative virulenceassociated functions. Microbiology 151:1095-1111.

67. de Lorenzo V, Herrero M, Neilands JB. 1988. IS1-mediated mobility of the aerobactin system of pColV-K30 in Escherichia coli. Mol Gen Genet 213:487-490.

68. Perez-Casal JF, Crosa JH. 1984. Aerobactin iron uptake sequences in plasmid ColV-K30 are flanked by inverted IS1-like elements and replication regions. J Bacteriol 160:256-265.

69. Valvano MA, Crosa JH. 1988. Molecular cloning, expression, and regulation in Escherichia coli K-12 of a chromosome-mediated aerobactin iron transport system from a human invasive isolate of E. coli K1. J Bacteriol 170:5529-5538.

70. Lawlor KM, Payne SM. 1984. Aerobactin genes in Shigella spp. J Bacteriol 160:266-272.

71. Purdy GE, Payne SM. 2001. The SHI-3 iron transport island of Shigella boydii 0-1392 carries the genes for aerobactin synthesis and transport. J Bacteriol 183:4176-4182.

72. Valvano MA, Crosa JH. 1984. Aerobactin iron transport genes commonly encoded by certain ColV plasmids occur in the chromosome of a human invasive strain of Escherichia coli K1. Infect Immun 46:159-167.

73. Vokes SA, Reeves SA, Torres AG, Payne SM. 1999. The aerobactin iron transport system genes in Shigella flexneri are present within a pathogenicity island. Mol Microbiol 33:63-73.

74. Marolda CL, Valvano MA, Lawlor KM, Payne SM, Crosa JH. 1987. Flanking and internal regions of chromosomal genes mediating aerobactin iron uptake systems in enteroinvasive Escherichia coli and Shigella flexneri. J Gen Microbiol 133:2269-2278.

75. Nassif X, Sansonetti PJ. 1986. Correlation of the virulence of Klebsiella pneumoniae $\mathrm{K} 1$ and $\mathrm{K} 2$ with the presence of a plasmid encoding aerobactin. Infect Immun 54:603-608.

76. Carbonetti NH, Williams PH. 1984. A cluster of five genes specifying the aerobactin iron uptake system of plasmid ColV-K30. Infect Immun 46:7-12. 77. de Lorenzo V, Bindereif A, Paw BH, Neilands JB. 1986. Aerobactin biosynthesis and transport genes of plasmid ColV-K30 in Escherichia coli K-12. J Bacteriol 165:570-578.

78. de Lorenzo V, Neilands JB. 1986. Characterization of iucA and $i u c C$ genes of the aerobactin system of plasmid ColV-K30 in Escherichia coli. J Bacteriol 167:350-355. 
79. Wooldridge KG, Morrissey JA, Williams PH. 1992. Transport of ferric-aerobactin into the periplasm and cytoplasm of Escherichia coli K12: role of envelope-associated proteins and effect of endogenous siderophores. J Gen Microbiol 138:597-603.

80. Coulton JW, Mason P, Allatt DD. 1987. $f h u C$ and $f h u D$ genes for iron (III)-ferrichrome transport into Escherichia coli K-12. J Bacteriol 169: 3844-3849.

81. Fecker L, Braun V. 1983. Cloning and expression of the fhu genes involved in iron(III)-hydroxamate uptake by Escherichia coli. J Bacteriol 156:1301-1314.

82. Koster W, Braun V. 1990. Iron (III) hydroxamate transport into Escherichia coli. Substrate binding to the periplasmic FhuD protein. J Biol Chem 265:21407-21410.

83. Braun V, Burkhardt R, Schneider R, Zimmermann L. 1982. Chromosomal genes for ColV plasmid-determined iron(III)-aerobactin transport in Escherichia coli. J Bacteriol 151:553-559.

84. Braun V, Burkhardt R. 1982. Regulation of the ColV plasmiddetermined iron (III)-aerobactin transport system in Escherichia coli. $J$ Bacteriol 152:223-231.

85. Escolar L, Perez-Martin J, de Lorenzo V. 2000. Evidence of an unusually long operator for the fur repressor in the aerobactin promoter of Escherichia coli. J Biol Chem 275:24709-24714.

86. Carbonetti NH, Boonchai S, Parry SH, Vaisanen-Rhen V, Korhonen TK, Williams PH. 1986. Aerobactin-mediated iron uptake by Escherichia coli isolates from human extraintestinal infections. Infect Immun 51:966968.

87. Johnson JR, Moseley SL, Roberts PL, Stamm WE. 1988. Aerobactin and other virulence factor genes among strains of Escherichia coli causing urosepsis: association with patient characteristics. Infect Immun 56:405412 .

88. Lafont JP, Dho M, D’Hauteville HM, Bree A, Sansonetti PJ. 1987. Presence and expression of aerobactin genes in virulent avian strains of Escherichia coli. Infect Immun 55:193-197.

89. Tivendale KA, Allen JL, Ginns CA, Crabb BS, Browning GF. 2004. Association of iss and iucA, but not $t s h$, with plasmid-mediated virulence of avian pathogenic Escherichia coli. Infect Immun 72:65546560 .

90. Dozois CM, Daigle F, Curtiss R, 3rd. 2003. Identification of pathogenspecific and conserved genes expressed in vivo by an avian pathogenic Escherichia coli strain. Proc Natl Acad Sci USA 100:247-252.

91. Gao Q, Wang X, Xu H, Xu Y, Ling J, Zhang D, Gao S, Liu X. 2012. Roles of iron acquisition systems in virulence of extraintestinal pathogenic Escherichia coli: salmochelin and aerobactin contribute more to virulence than heme in a chicken infection model. BMC Microbiol 12:143.

92. Ling J, Pan H, Gao Q, Xiong L, Zhou Y, Zhang D, Gao S, Liu X. 2013. Aerobactin synthesis genes iucA and iucC contribute to the pathogenicity of avian pathogenic Escherichia coli O2 strain E058. PLoS One 8:e57794. doi:10.1371/journal.pone.0057794.

93. Lemaitre C, Bidet P, Bingen E, Bonacorsi S. 2012. Transcriptional analysis of the Escherichia coli ColV-Ia plasmid pS88 during growth in human serum and urine. BMC Microbiol 12:115.

94. Lemaitre C, Mahjoub-Messai F, Dupont D, Caro V, Diancourt L, Bingen E, Bidet P, Bonacorsi S. 2013. A conserved virulence plasmidic region contributes to the virulence of the multiresistant Escherichia coli meningitis strain S286 belonging to phylogenetic group C. PLoS One 8: e74423. doi:10.1371/journal.pone.0074423.

95. Baumler AJ, Norris TL, Lasco T, Voight W, Reissbrodt R, Rabsch W, Heffron F. 1998. IroN, a novel outer membrane siderophore receptor characteristic of Salmonella enterica. J Bacteriol 180:14461453.

96. Baumler AJ, Tsolis RM, van der Velden AW, Stojiljkovic I, Anic S, Heffron F. 1996. Identification of a new iron regulated locus of Salmonella typhi. Gene 183:207-213.
97. Brzuszkiewicz E, Bruggemann $H$, Liesegang $H$, Emmerth $M$, Olschlager T, Nagy G, Albermann K, Wagner C, Buchrieser C, Emody L, Gottschalk G, Hacker J, Dobrindt U. 2006. How to become a uropathogen: comparative genomic analysis of extraintestinal pathogenic Escherichia coli strains. Proc Natl Acad Sci USA 103:12879-12884.

98. Dobrindt U, Blum-Oehler G, Nagy G, Schneider G, Johann A, Gottschalk G, Hacker J. 2002. Genetic structure and distribution of four pathogenicity islands (PAI I(536) to PAI IV(536)) of uropathogenic Escherichia coli strain 536. Infect Immun 70:6365-6372.

99. Lin H, Fischbach MA, Liu DR, Walsh CT. 2005. In vitro characterization of salmochelin and enterobactin trilactone hydrolases IroD, IroE, and Fes. J Am Chem Soc 127:11075-11084.

100. Liu Q, Ma Y, Wu H, Shao M, Liu H, Zhang Y. 2004. Cloning, identification and expression of an entE homologue angE from Vibrio anguillarum serotype O1. Arch Microbiol 181:287-293.

101. Chen YT, Chang HY, Lai YC, Pan CC, Tsai SF, Peng HL. 2004. Sequencing and analysis of the large virulence plasmid pLVPK of Klebsiella pneumoniae CG43. Gene 337:189-198.

102. Sorsa LJ, Dufke S, Heesemann J, Schubert S. 2003. Characterization of an iroBCDEN gene cluster on a transmissible plasmid of uropathogenic Escherichia coli: evidence for horizontal transfer of a chromosomal virulence factor. Infect Immun 71:3285-3293.

103. Bister B, Bischoff D, Nicholson GJ, Valdebenito M, Schneider K, Winkelmann G, Hantke K, Sussmuth RD. 2004. The structure of salmochelins: C-glucosylated enterobactins of Salmonella enterica. Biometals 17:471-481.

104. Fischbach MA, Lin H, Liu DR, Walsh CT. 2005. In vitro characterization of IroB, a pathogen-associated C-glycosyltransferase. Proc Natl Acad Sci USA 102:571-576.

105. Fischbach MA, Lin H, Zhou L, Yu Y, Abergel RJ, Liu DR, Raymond KN, Wanner BL, Strong RK, Walsh CT, Aderem A, Smith KD. 2006. The pathogen-associated iroA gene cluster mediates bacterial evasion of lipocalin 2. Proc Natl Acad Sci USA 103:16502-16507.

106. Goetz DH, Holmes MA, Borregaard N, Bluhm ME, Raymond KN, Strong RK. 2002. The neutrophil lipocalin NGAL is a bacteriostatic agent that interferes with siderophore-mediated iron acquisition. Mol Cell 10:1033-1043.

107. Hantke K, Nicholson G, Rabsch W, Winkelmann G. 2003. Salmochelins, siderophores of Salmonella enterica and uropathogenic Escherichia coli strains, are recognized by the outer membrane receptor IroN. Proc Natl Acad Sci USA 100:3677-3682.

108. Rabsch W, Voigt W, Reissbrodt R, Tsolis RM, Baumler AJ. 1999. Salmonella typhimurium IroN and FepA proteins mediate uptake of enterobactin but differ in their specificity for other siderophores. J Bacteriol 181:3610-3612.

109. Feldmann F, Sorsa LJ, Hildinger K, Schubert S. 2007. The salmochelin siderophore receptor IroN contributes to invasion of urothelial cells by extraintestinal pathogenic Escherichia coli in vitro. Infect Immun 75: 3183-3187.

110. Caza M, Lepine F, Milot S, Dozois CM. 2008. Specific roles of the iroBCDEN genes in virulence of an avian pathogenic Escherichia coli O78 strain and in production of salmochelins. Infect Immun 76:3539-3549.

111. Crouch ML, Castor M, Karlinsey JE, Kalhorn T, Fang FC. 2008. Biosynthesis and IroC-dependent export of the siderophore salmochelin are essential for virulence of Salmonella enterica serovar Typhimurium. Mol Microbiol 67:971-983.

112. Zhu M, Valdebenito M, Winkelmann G, Hantke K. 2005. Functions of the siderophore esterases IroD and IroE in iron-salmochelin utilization. Microbiology 151:2363-2372.

113. Muller SI, Valdebenito M, Hantke K. 2009. Salmochelin, the longoverlooked catecholate siderophore of Salmonella. Biometals 22:691-695. 114. Skyberg JA, Johnson TJ, Nolan LK. 2008. Mutational and transcriptional analyses of an avian pathogenic Escherichia coli ColV plasmid. BMC Microbiol 8:24. 
115. Lemaitre C, Bidet P, Benoist JF, Schlemmer D, Sobral E, d'Humieres C, Bonacorsi S. 2014. The ssbL gene harbored by the ColV plasmid of an Escherichia coli neonatal meningitis strain is an auxiliary virulence factor boosting the production of siderophores through the shikimate pathway. J Bacteriol 196:1343-1349.

116. Sabri M, Leveille S, Dozois CM. 2006. A SitABCD homologue from an avian pathogenic Escherichia coli strain mediates transport of iron and manganese and resistance to hydrogen peroxide. Microbiology 152:745758 .

117. Tivendale KA, Allen JL, Browning GF. 2009. Plasmid-borne virulenceassociated genes have a conserved organization in virulent strains of avian pathogenic Escherichia coli. J Clin Microbiol 47:2513-2519.

118. Zhou D, Hardt WD, Galan JE. 1999. Salmonella typhimurium encodes a putative iron transport system within the centisome 63 pathogenicity island. Infect Immun 67:1974-1981.

119. Runyen-Janecky LJ, Reeves SA, Gonzales EG, Payne SM. 2003. Contribution of the Shigella flexneri Sit, Iuc, and Feo iron acquisition systems to iron acquisition in vitro and in cultured cells. Infect Immun 71:1919-1928.

120. Janakiraman A, Slauch JM. 2000. The putative iron transport system SitABCD encoded on SPI1 is required for full virulence of Salmonella typhimurium. Mol Microbiol 35:1146-1155.

121. Boyer E, Bergevin I, Malo D, Gros P, Cellier MF. 2002. Acquisition of $\mathrm{Mn}(\mathrm{II})$ in addition to $\mathrm{Fe}(\mathrm{II})$ is required for full virulence of Salmonella enterica serovar Typhimurium. Infect Immun 70:6032-6042.

122. Runyen-Janecky L, Dazenski E, Hawkins S, and Warner L. 2006. Role and regulation of the Shigella flexneri Sit and MntH systems. Infect Immun 74:4666-4672.

123. Sabri M, Caza M, Proulx J, Lymberopoulos MH, Bree A, MoulinSchouleur M, Curtiss R, 3rd, Dozois CM. 2008. Contribution of the SitABCD, MntH, and FeoB metal transporters to the virulence of avian pathogenic Escherichia coli O78 strain chi7122. Infect Immun 76:601-611. 124. Ewers C, Li G, Wilking H, Kiessling S, Alt K, Antao EM, Laturnus C, Diehl I, Glodde S, Homeier T, Bohnke U, Steinruck H, Philipp HC, Wieler LH. 2007. Avian pathogenic, uropathogenic, and newborn meningitiscausing Escherichia coli: how closely related are they? Int J Med Microbiol 297:163-176.

125. Mellata M, Ameiss K, Mo H, Curtiss R, 3rd. 2010. Characterization of the contribution to virulence of three large plasmids of avian pathogenic Escherichia coli chi7122 (O78:K80:H9). Infect Immun 78:1528-1541.

126. Mellata M, Maddux JT, Nam T, Thomson N, Hauser H, Stevens MP, Mukhopadhyay S, Sarker S, Crabbe A, Nickerson CA, Santander J, Curtiss R, 3rd. 2012. New insights into the bacterial fitness-associated mechanisms revealed by the characterization of large plasmids of an avian pathogenic E. coli. PLoS One 7:e29481. doi:10.1371/journal.pone .0029481 .

127. Yi H, Xi Y, Liu J, Wang J, Wu J, Xu T, Chen W, Chen B, Lin M, Wang H, Zhou M, Li J, Xu Z, Jin S, Bao Q. 2010. Sequence analysis of pKF3-70 in Klebsiella pneumoniae: probable origin from R100-like plasmid of Escherichia coli. PLoS One 5:e8601. doi:10.1371/journal .pone.0008601.

128. Provence DL, Curtiss R, 3rd. 1994. Isolation and characterization of a gene involved in hemagglutination by an avian pathogenic Escherichia coli strain. Infect Immun 62:1369-1380.

129. Leo JC, Grin I, Linke D. 2012. Type V secretion: mechanism(s) of autotransport through the bacterial outer membrane. Philos Trans $R$ Soc Lond B Biol Sci 367:1088-1101.

130. Stathopoulos C, Provence DL, Curtiss R, 3rd. 1999. Characterization of the avian pathogenic Escherichia coli hemagglutinin Tsh, a member of the immunoglobulin A protease-type family of autotransporters. Infect Immun 67:772-781.

131. Otto BR, van Dooren SJ, Nuijens JH, Luirink J, Oudega B. 1998. Characterization of a hemoglobin protease secreted by the pathogenic Escherichia coli strain EB1. J Exp Med 188:1091-1103.
132. Dozois CM, Dho-Moulin M, Bree A, Fairbrother JM, Desautels C, Curtiss R, 3rd. 2000. Relationship between the Tsh autotransporter and pathogenicity of avian Escherichia coli and localization and analysis of the Tsh genetic region. Infect Immun 68:4145-4154.

133. Kaczmarek A, Budzynska A, Gospodarek E. 2012. Prevalence of genes encoding virulence factors among Escherichia coli with K1 antigen and non-K1 E. coli strains. J Med Microbiol 61:1360-1365.

134. Beutin L. 1991. The different hemolysins of Escherichia coli. Med Microbiol Immunol 180:167-182.

135. Morales C, Lee MD, Hofacre C, Maurer JJ. 2004. Detection of a novel virulence gene and a Salmonella virulence homologue among Escherichia coli isolated from broiler chickens. Foodborne Pathog Dis 1:160-165.

136. Reingold J, Starr N, Maurer J, Lee MD. 1999. Identification of a new Escherichia coli She haemolysin homolog in avian E. coli. Vet Microbiol 66:125-134.

137. Welch RA. 1991. Pore-forming cytolysins of gram-negative bacteria. Mol Microbiol 5:521-528.

138. Burgos Y, Beutin L. 2010. Common origin of plasmid encoded alpha-hemolysin genes in Escherichia coli. BMC Microbiol 10:193.

139. Muller D, Hughes C, Goebel W. 1983. Relationship between plasmid and chromosomal hemolysin determinants of Escherichia coli.J Bacteriol 153:846-851.

140. Schmidt H, Beutin L, Karch H. 1995. Molecular analysis of the plasmid-encoded hemolysin of Escherichia coli O157:H7 strain EDL 933. Infect Immun 63:1055-1061.

141. Schmidt H, Kernbach C, Karch H. 1996. Analysis of the EHEC bly operon and its location in the physical map of the large plasmid of enterohaemorrhagic Escherichia coli O157:H7. Microbiology 142:907-914.

142. Brunder W, Karch H, Schmidt H. 2006. Complete sequence of the large virulence plasmid pSFO157 of the sorbitol-fermenting enterohemorrhagic Escherichia coli O157:H- strain 3072/96. Int J Med Microbiol 296:467-474.

143. Burland V, Shao Y, Perna NT, Plunkett G, Sofia HJ, Blattner FR. 1998. The complete DNA sequence and analysis of the large virulence plasmid of Escherichia coli O157:H7. Nucleic Acids Res 26:4196-4204.

144. Cavalieri SJ, Bohach GA, Snyder IS. 1984. Escherichia coli alphahemolysin: characteristics and probable role in pathogenicity. Microbiol Rev 48:326-343.

145. de la Cruz F, Muller D, Ortiz JM, Goebel W. 1980. Hemolysis determinant common to Escherichia coli hemolytic plasmids of different incompatibility groups. J Bacteriol 143:825-833.

146. Burgos YK, Pries K, Pestana de Castro AF, Beutin L. 2009. Characterization of the alpha-haemolysin determinant from the human enteropathogenic Escherichia coli $\mathrm{O} 26$ plasmid pEO5. FEMS Microbiol Lett 292:194-202.

147. Bakás L, Maté S, Vazquez R, Herlax V. 2012. E. coli alpha hemolysin and properties. In Ekinci PD (ed), Biochemistry. InTech ship, Rijeka, Croatia.

148. Lebek G, Gruenig HM. 1985. Relation between the hemolytic property and iron metabolism in Escherichia coli. Infect Immun 50:682-686. 149. Nataro JP, Kaper JB. 1998. Diarrheagenic Escherichia coli. Clin Microbiol Rev 11:142-201.

150. Nagy G, Dobrindt U, Kupfer M, Emody L, Karch H, Hacker J. 2001. Expression of hemin receptor molecule ChuA is influenced by $\mathrm{RfaH}$ in uropathogenic Escherichia coli strain 536. Infect Immun 69:1924-1928.

151. Han J, Lynne AM, David DE, Tang H, Xu J, Nayak R, Kaldhone P, Logue CM, Foley SL. 2012. DNA sequence analysis of plasmids from multidrug resistant Salmonella enterica serotype Heidelberg isolates. PLoS One 7:e51160. doi:10.1371/journal.pone.0051160.

152. Fricke WF, Wright MS, Lindell AH, Harkins DM, Baker-Austin C, Ravel J, Stepanauskas R. 2008. Insights into the environmental resistance gene pool from the genome sequence of the multidrug-resistant environmental isolate Escherichia coli SMS-3-5. J Bacteriol 190:6779-6794. 
153. Naka H, Crosa JH. 2011. Genetic determinants of virulence in the marine fish pathogen Vibrio anguillarum. Fish Pathol 46:1-10.

154. Crosa JH, Schiewe MH, Falkow S. 1977. Evidence for plasmid contribution to the virulence of fish pathogen Vibrio anguillarum. Infect Immun 18:509-513.

155. Crosa JH, Hodges LL, Schiewe MH. 1980. Curing of a plasmid is correlated with an attenuation of virulence in the marine fish pathogen Vibrio anguillarum. Infect Immun 27:897-902.

156. Crosa JH. 1984. The relationship of plasmid-mediated iron transport and bacterial virulence. Annu Rev Microbiol 38:69-89.

157. Crosa JH. 1980. A plasmid associated with virulence in the marine fish pathogen Vibrio anguillarum specifies an iron-sequestering system. Nature 284:566-568.

158. Wolf MK, Crosa JH. 1986. Evidence for the role of a siderophore in promoting Vibrio anguillarum infections. J Gen Microbiol 132:29492952.

159. Mitoma Y, Aoki T, Crosa JH. 1984. Phylogenetic relationships among Vibrio anguillarum plasmids. Plasmid 12:143-148.

160. Tolmasky ME, Actis LA, Toranzo AE, Barja JL, Crosa JH. 1985. Plasmids mediating iron uptake in Vibrio anguillarum strains isolated from turbot in Spain. J Gen Microbiol 131:1989-1997.

161. Di Lorenzo M, Stork M, Tolmasky ME, Actis LA, Farrell D, Welch TJ, Crosa LM, Wertheimer AM, Chen Q, Salinas P, Waldbeser L, Crosa JH. 2003. Complete sequence of virulence plasmid pJM1 from the marine fish pathogen Vibrio anguillarum strain 775. J Bacteriol 185:5822-5830.

162. Olsen JE, Larsen JL. 1990. Restriction fragment length polymorphism of the Vibrio anguillarum serovar $\mathrm{O} 1$ virulence plasmid. Appl Environ Microbiol 56:3130-3132.

163. Li G, Mo Z, Li J, Xiao P, Hao B. 2013. Complete genome sequence of Vibrio anguillarum M3, a serotype O1 strain isolated from Japanese flounder in China. Genome Announc 1:e00769-13. doi:10.1128/genomeA .00769-13.

164. Wu H, Ma Y, Zhang Y, Zhang H. 2004. Complete sequence of virulence plasmid pEIB1 from the marine fish pathogen Vibrio anguillarum strain MVM425 and location of its replication region. J Appl Microbiol 97:1021-1028.

165. Chen Q. 1995. Molecular Microbiology and Immunology, Ph.D. thesis. Oregon Health and Science University, Portland, OR.

166. Naka H, Chen Q, Mitoma Y, Nakamura Y, McIntosh-Tolle D, Gammie AE, Tolmasky ME, Crosa JH. 2012. Two replication regions in the pJM1 virulence plasmid of the marine pathogen Vibrio anguillarum. Plasmid 67:95-101.

167. Singer JT, Choe W, Schmidt KA, Makula RA. 1992. Virulence plasmid pJM1 prevents the conjugal entry of plasmid DNA into the marine fish pathogen Vibrio anguillarum 775. J Gen Microbiol 138:24852490.

168. Larsen JL, Olsen JE. 1991. Occurrence of plasmids in Danish isolates of Vibrio anguillarum serovars $\mathrm{O} 1$ and $\mathrm{O} 2$ and association of plasmids with phenotypic characteristics. Appl Environ Microbiol 57:2158-2163.

169. Actis LA, Fish W, Crosa JH, Kellerman K, Ellenberger SR, Hauser FM, Sanders-Loehr J. 1986. Characterization of anguibactin, a novel siderophore from Vibrio anguillarum 775(pJM1). J Bacteriol 167: 57-65.

170. Tolmasky ME, Actis LA, Crosa JH. 1988. Genetic analysis of the iron uptake region of the Vibrio anguillarum plasmid pJM1: molecular cloning of genetic determinants encoding a novel trans activator of siderophore biosynthesis. J Bacteriol 170:1913-1919.

171. Tolmasky ME, Crosa JH. 1984. Molecular cloning and expression of genetic determinants for the iron uptake system mediated by the Vibrio anguillarum plasmid pJM1. J Bacteriol 160:860-866.

172. Walter MA, Potter SA, Crosa JH. 1983. Iron uptake system medicated by Vibrio anguillarum plasmid pJM1. J Bacteriol 156:880-887.
173. Walsh CT, Marshall CG. 2004. Siderophore biosynthesis in bacteria, p 18-37. In Crosa JH, Mey AR, Payne SM (ed), Iron Transport in Bacteria. ASM Press, Washington, DC.

174. Chen Q, Actis LA, Tolmasky ME, Crosa JH. 1994. Chromosomemediated 2,3-dihydroxybenzoic acid is a precursor in the biosynthesis of the plasmid-mediated siderophore anguibactin in Vibrio anguillarum. J Bacteriol 176:4226-4234.

175. Alice AF, Lopez CS, Crosa JH. 2005. Plasmid- and chromosomeencoded redundant and specific functions are involved in biosynthesis of the siderophore anguibactin in Vibrio anguillarum 775: a case of chance and necessity? J Bacteriol 187:2209-2214.

176. Welch TJ, Chai S, Crosa JH. 2000. The overlapping angB and angG genes are encoded within the trans-acting factor region of the virulence plasmid in Vibrio anguillarum: essential role in siderophore biosynthesis. J Bacteriol 182:6762-6773.

177. Barancin CE, Smoot JC, Findlay RH, Actis LA. 1998. Plasmidmediated histamine biosynthesis in the bacterial fish pathogen Vibrio anguillarum. Plasmid 39:235-244.

178. Tolmasky ME, Actis LA, Crosa JH. 1995. A histidine decarboxylase gene encoded by the Vibrio anguillarum plasmid pJM1 is essential for virulence: histamine is a precursor in the biosynthesis of anguibactin. Mol Microbiol 15:87-95.

179. Di Lorenzo M, Stork M, Crosa JH. 2011. Genetic and biochemical analyses of chromosome and plasmid gene homologues encoding ICL and ArCP domains in Vibrio anguillarum strain 775. Biometals 24:629-643. 180. Liu Q, Ma Y, Zhou L, Zhang Y. 2005. Gene cloning, expression and functional characterization of a phosphopantetheinyl transferase from Vibrio anguillarum serotype O1. Arch Microbiol 183:37-44.

181. Di Lorenzo M, Poppelaars S, Stork M, Nagasawa M, Tolmasky ME, Crosa JH. 2004. A nonribosomal peptide synthetase with a novel domain organization is essential for siderophore biosynthesis in Vibrio anguillarum. J Bacteriol 186:7327-7336.

182. Di Lorenzo M, Stork M, Naka H, Tolmasky ME, Crosa JH. 2008. Tandem heterocyclization domains in a nonribosomal peptide synthetase essential for siderophore biosynthesis in Vibrio anguillarum. Biometals 21:635-648.

183. Jalal M, Hossain D, van der Helm D, Sanders-Loehr J, Actis LA, Crosa JH. 1989. Structure of anguibactin, a unique plasmid-related bacterial siderophore from the fish pathogen Vibrio anguillarum. J Am Chem Soc 111:292-296.

184. Actis LA, Tolmasky ME, Farrell DH, Crosa JH. 1988. Genetic and molecular characterization of essential components of the Vibrio anguillarum plasmid-mediated iron-transport system. J Biol Chem 263:28532860.

185. Actis LA, Potter SA, Crosa JH. 1985. Iron-regulated outer membrane protein OM2 of Vibrio anguillarum is encoded by virulence plasmid pJM1. J Bacteriol 161:736-742.

186. Crosa JH, Hodges LL. 1981. Outer membrane proteins induced under conditions of iron limitation in the marine fish pathogen Vibrio anguillarum 775 . Infect Immun 31:223-227.

187. Lopez CS, Alice AF, Chakraborty R, Crosa JH. 2007. Identification of amino acid residues required for ferric-anguibactin transport in the outer-membrane receptor FatA of Vibrio anguillarum. Microbiology 153: 570-584.

188. Stork M, Di Lorenzo M, Mourino S, Osorio CR, Lemos ML, Crosa JH. 2004. Two tonB systems function in iron transport in Vibrio anguillarum, but only one is essential for virulence. Infect Immun 72:7326-7329. 189. Actis LA, Tolmasky ME, Crosa LM, Crosa JH. 1995. Characterization and regulation of the expression of $\mathrm{FatB}$, an iron transport protein encoded by the pJM1 virulence plasmid. Mol Microbiol 17:197-204.

190. Koster WL, Actis LA, Waldbeser LS, Tolmasky ME, Crosa JH. 1991. Molecular characterization of the iron transport system mediated by the pJM1 plasmid in Vibrio anguillarum 775. J Biol Chem 266:23829-23833. 
191. Naka H, Lopez CS, Crosa JH. 2010. Role of the pJM1 plasmidencoded transport proteins FatB, C and D in ferric anguibactin uptake in the fish pathogen Vibrio anguillarum. Environ Microbiol Rep 2:104111.

192. Naka H, Liu M, Crosa JH. 2013. Two ABC transporter systems participate in siderophore transport in the marine pathogen Vibrio anguillarum 775 (pJM1). FEMS Microbiol Lett 341:79-86.

193. Balado M, Osorio CR, Lemos ML. 2006. A gene cluster involved in the biosynthesis of vanchrobactin, a chromosome-encoded siderophore produced by Vibrio anguillarum. Microbiology 152:3517-3528.

194. Iglesias E, Brandariz I, Jimenez C, Soengas RG. 2011. Iron(III) complexation by vanchrobactin, a siderophore of the bacterial fish pathogen Vibrio anguillarum. Metallomics 3:521-528.

195. Naka H, Lopez CS, Crosa JH. 2008. Reactivation of the vanchrobactin siderophore system of Vibrio anguillarum by removal of a chromosomal insertion sequence originated in plasmid pJM1 encoding the anguibactin siderophore system. Environ Microbiol 10:265-277.

196. Farrell DH, Mikesell P, Actis LA, Crosa JH. 1990. A regulatory gene, $\operatorname{angR}$, of the iron uptake system of Vibrio anguillarum: similarity with phage P22 cro and regulation by iron. Gene 86:45-51.

197. Salinas PC, Crosa JH. 1995. Regulation of angR, a gene with regulatory and biosynthetic functions in the pJM1 plasmid-mediated iron uptake system of Vibrio anguillarum. Gene 160:17-23.

198. Salinas PC, Tolmasky ME, Crosa JH. 1989. Regulation of the iron uptake system in Vibrio anguillarum: evidence for a cooperative effect between two transcriptional activators. Proc Natl Acad Sci USA 86:35293533.

199. Wertheimer AM, Verweij W, Chen Q, Crosa LM, Nagasawa M, Tolmasky ME, Actis LA, Crosa JH. 1999. Characterization of the angR gene of Vibrio anguillarum: essential role in virulence. Infect Immun 67:6496-6509.

200. Tolmasky ME, Wertheimer AM, Actis LA, Crosa JH. 1994. Characterization of the Vibrio anguillarum fur gene: role in regulation of expression of the FatA outer membrane protein and catechols. J Bacteriol 176:213-220.

201. Wertheimer AM, Tolmasky ME, Actis LA, Crosa JH. 1994. Structural and functional analyses of mutant Fur proteins with impaired regulatory function. J Bacteriol 176:5116-5122.

202. Chai S, Welch TJ, Crosa JH. 1998. Characterization of the interaction between Fur and the iron transport promoter of the virulence plasmid in Vibrio anguillarum. J Biol Chem 273:33841-33847.
203. Chen Q, Crosa JH. 1996. Antisense RNA, Fur, iron, and the regulation of iron transport genes in Vibrio anguillarum. J Biol Chem 271:18885-18891. 204. Waldbeser LS, Chen Q, Crosa JH. 1995. Antisense RNA regulation of the $f a t B$ iron transport protein gene in Vibrio anguillarum. Mol Microbiol 17:747-756.

205. Salinas PC, Waldbeser LS, Crosa JH. 1993. Regulation of the expression of bacterial iron transport genes: possible role of an antisense RNA as a repressor. Gene 123:33-38.

206. Stork M, Di Lorenzo M, Welch TJ, Crosa JH. 2007. Transcription termination within the iron transport-biosynthesis operon of Vibrio anguillarum requires an antisense RNA. J Bacteriol 189:3479-3488.

207. McIntosh-Tolle D, Stork M, Alice A, Crosa JH. 2012. Secondary structure of antisense RNA $\beta$, an internal transcriptional terminator of the plasmid-encoded iron transport-biosynthesis operon of Vibrio anguillarum. Biometals 25:577-586.

208. Tolmasky ME, Actis LA, Crosa JH. 1993. A single amino acid change in AngR, a protein encoded by pJM1-like virulence plasmids, results in hyperproduction of anguibactin. Infect Immun 61:3228-3233. 209. Tolmasky ME, Salinas PC, Actis LA, Crosa JH. 1988. Increased production of the siderophore anguibactin mediated by pJM1-like plasmids in Vibrio anguillarum. Infect Immun 56:1608-1614.

210. Bay L, Larsen JL, Leisner JJ. 2007. Distribution of three genes involved in the pJM1 iron-sequestering system in various Vibrio anguillarum serogroups. Syst Appl Microbiol 30:85-92.

211. Naka H, Actis LA, Crosa JH. 2013. The anguibactin biosynthesis and transport genes are encoded in the chromosome of Vibrio harveyi: a possible evolutionary origin for the pJM1 plasmid-encoded system of Vibrio anguillarum? MicrobiolOgyopen 2:182-194.

212. Johnson TJ, Jordan D, Kariyawasam S, Stell AL, Bell NP, Wannemuehler YM, Alarcon CF, Li G, Tivendale KA, Logue CM, Nolan LK. 2010. Sequence analysis and characterization of a transferable hybrid plasmid encoding multidrug resistance and enabling zoonotic potential for extraintestinal Escherichia coli. Infect Immun 78:1931-1942.

213. Johnson TJ, Wannemuehler Y, Johnson SJ, Stell AL, Doetkott C, Johnson JR, Kim KS, Spanjaard L, Nolan LK. 2008. Comparison of extraintestinal pathogenic Escherichia coli strains from human and avian sources reveals a mixed subset representing potential zoonotic pathogens. Appl Environ Microbiol 74:7043-7050.

214. Tivendale KA, Noormohammadi AH, Allen JL, Browning GF. 2009. The conserved portion of the putative virulence region contributes to virulence of avian pathogenic Escherichia coli. Microbiology 155:450-460. 